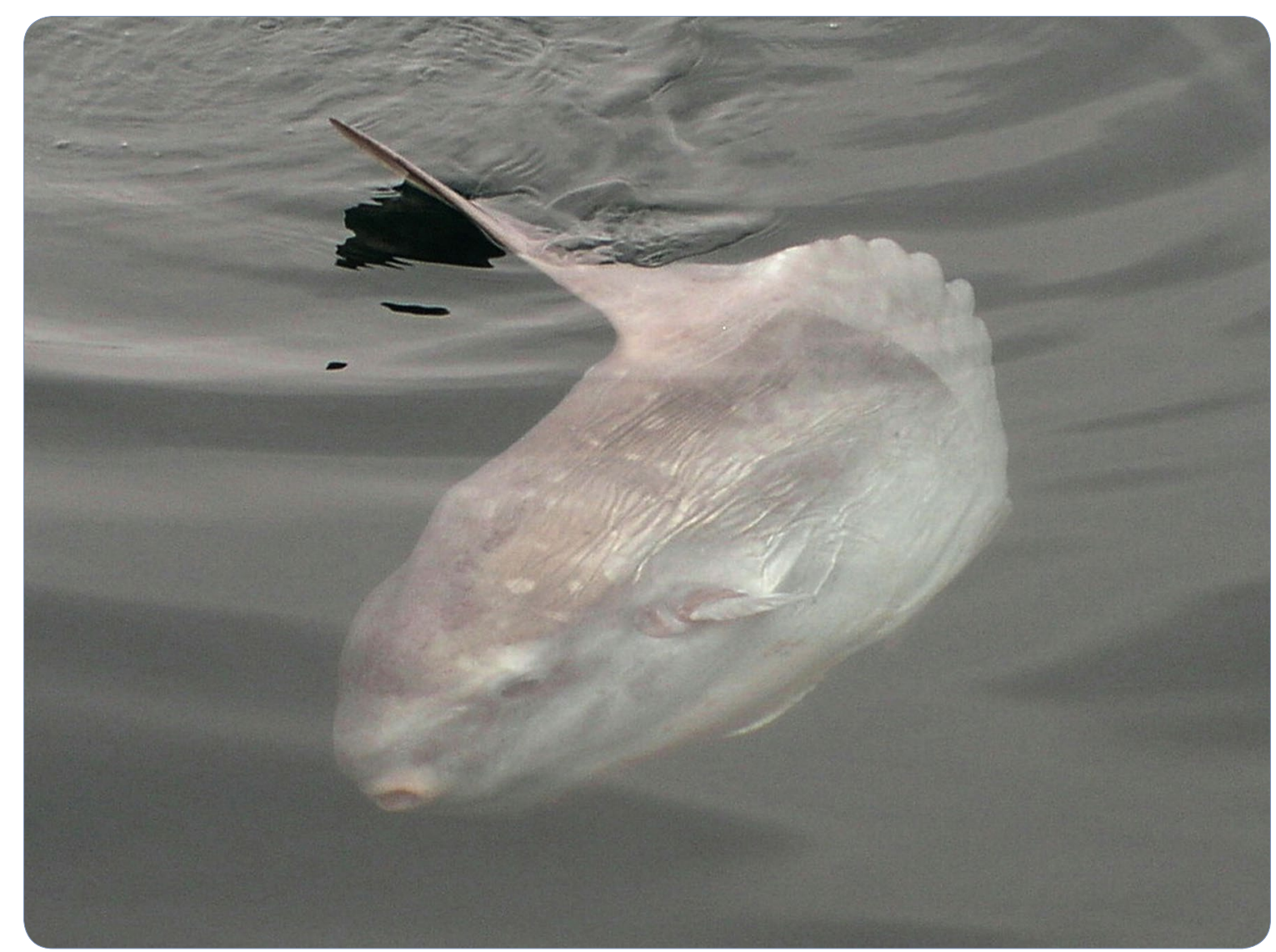

Environmental influence on the seasonal movements of satellite-tracked ocean sunfish Mola mola in the north-east Atlantic

Sousa et al. 


\title{
Environmental influence on the seasonal movements of satellite-tracked ocean sunfish Mola mola in the north-east Atlantic
}

\author{
Lara L. Sousa ${ }^{1,2,3}$, Nuno Queiroz ${ }^{1,2}$, Gonzalo Mucientes ${ }^{2,4}$, Nicolas E. Humphries ${ }^{1}$ and David W. Sims , $^{1,55^{*}}$
}

\begin{abstract}
Background: Determining the habitat use of mobile marine species is important for understanding responses to climate change and aids the implementation of management and conservation measures. Inference of preferred habitat use has been greatly improved by combining satellite-based oceanographic data with animal tracking techniques. Although there have been several satellite-tracking studies on ocean sunfish Mola mola, limited information is available about either horizontal or vertical environmental preferences. In this study, both geographical movements and diving behaviour of ocean sunfish were explored together with the environmental factors influencing this species'space use in the north-east Atlantic.

Results: Habitat selection of electronic-tagged sunfish ( $n=22$ individuals; $0.6-1.4 \mathrm{~m}$ total length, $\mathrm{TL}$ ) was investigated using geolocations from Argos-linked and pop-up satellite archival transmitters. Satellite tracking (up to 171 days, mean 66 days) revealed seasonal movements: northward in spring-summer and southward in cooler months. Sunfish spent extended periods in three focal areas, the Gulf of Cadiz, north-east Iberia and the Alboran gyre, which are characterised by the presence of frontal features with elevated primary production. Habitat modelling revealed that sea surface temperature and thermal gradients significantly influenced sunfish distribution. Diving profiles, extending from the surface to a maximum depth of $704 \mathrm{~m}$, revealed different depth-use patterns not linked to geographical region or water column stratification. Overall, a size-related movement pattern was detected with larger individuals $(>0.92 \mathrm{~m} \mathrm{TL}$ ) travelling further, exploiting greater depth ranges and spending more time at depth than smaller fish.

Conclusions: Ocean sunfish in the north-east Atlantic displayed seasonal movements, primarily driven by thermal preferences, extending into higher latitudes in summer. Moreover, fish also occupied productive frontal areas for long periods, presumably for improved foraging opportunities. Lastly, sunfish showed considerable variability in diving patterns which likely reflect the tracking of planktonic prey distributions.
\end{abstract}

Keywords: Biologging, Habitat selection, Home range, Nursery area, Residency, Reverse DVM, Telemetry

\section{Background}

Knowledge of seasonal movements and migratory routes is crucial for understanding the distribution of animal populations and represents a first step in the investigation of the ecological mechanisms underlying spatial dynamics $[1,2]$. In marine animals that spend short

\footnotetext{
*Correspondence: dws@mba.ac.uk

${ }^{1}$ Marine Biological Association of the United Kingdom, The Laboratory,

Citadel Hill, Plymouth PL1 2PB, UK

Full list of author information is available at the end of the article
}

periods of time at the water's surface, such as pelagic fish, the understanding of seasonal movements is complicated by the difficulty of making sustained direct observations over the larger spatial scales relevant to migration [3]. However, in recent years, techniques such as electronic tagging have been developed to track marine species' individual movements [4-6] by deploying diverse tag types [6-9]. Coupled with remote sensing of environmental variables, satellite tracking has improved our knowledge of habitat selection patterns and fluctuations 
in environmental preferences [10]. While movements are a measurable behavioural response to a combination of factors including internal states, physiological constraints and environmental variations [3], the description of important habitats relies on identifying the features underpinning species distributions [11].

A number of environmental variables have been linked to species distributions. For instance, water temperature has been described as a major environmental driver of the movements of diverse marine species including bluefin tuna (Thunnus thynnus) [12], swordfish (Xiphias gladius) [13], blue shark (Prionace glauca) [8], mako shark (Isurus oxyrinchus) [14], salmon sharks (Lamna ditropis) [2] and loggerhead turtles (Caretta caretta) [15]. The aggregation of marine pelagic vertebrates in areas dominated by steep thermal gradients such as tidal and shelf-break fronts, upwelling regions, mesoscale eddies and oceanic fronts has also been documented widely [for review, see 16]. Chlorophyll $a$ was also found to influence the distribution and migration of marine predators such as loggerhead turtles and albacore tuna (Thunnus alalunga) [17] and whale sharks (Rhincodon typus) [18]. Hence, the importance of these oceanographic features is likely due to improved foraging opportunities [19].

Several analytical techniques have been developed in the past few decades to model species distributions, from traditional null hypothesis testing to a more complete framework to test competing hypotheses [see review in 20]. Current species distribution models usually relate field observations to environmental predictors, based on statistically or theoretically derived 'surfaces' of species response to the habitats [21]. From regression-based techniques, such as generalised linear and additive models, to more sophisticated machine learning informative models [22], the basic concept of combining observations of species occurrence or abundance with environmental estimates has been widely explored [23-26]. Nonlinear response, occurrence or abundance of species can now be modelled within the occupied environmental spatial area [e.g. 6, 23, 27]. Therefore, ecological relationships between species and their resources (physical and biotic) can be determined, providing a central approach in many current analytical methods, including resource selection probability functions (RSPFs) [28]. RSPFs are a machine learning technique where the utilised habitat is modelled versus the unutilised but available habitat [28-31]. This model quantitatively characterises the probability of usage by accommodating both categorical and continuous features or variables, while facilitating the spatial structure to be incorporated with, for example, remotely sensed environmental features [32]. When combined with geographical information systems, RSPFs can be a powerful tool for helping to understand potential resource usage of species.

The horizontal movements of the world's heaviest teleost, the ocean sunfish (Mola mola Linnaeus, 1758), have been examined in previous studies. Despite observed slow surface swimming speeds, sunfish are active swimmers capable of extensive horizontal and vertical movements independent of ocean currents [33]. These increased movement rates were verified over both fine and broader scales using spatially accurate global positioning system (GPS) tags [34]. Satellite-tracking studies in the North Atlantic and in the north-west Pacific oceans have demonstrated that this species undertakes northward movements in spring and southward in late summer/autumn, thus displaying spatial changes consistent with a seasonal, population-level migration linked to seasonal variations of sea surface temperature and/ or forage availability [34-37]. In the north-east Atlantic, the north-south migratory pattern may also be linked to increased abundance of preferred zooplankton prey at higher latitudes as waters seasonally warm [38].

Diel movement patterns were described for sunfish, with this species diving below the thermocline during daylight hours, while nocturnal dives were confined to the surface mixed layer [33, 34, 39]. Vertical distribution and space use of marine predators are expected to change in relation to characteristics of the water column, and/or due to alterations in the depth preferences of prey. Thus, the observed movements through the water column may well be an optimal foraging strategy [40], as extensive vertical movements increase the probability of encountering higher prey concentrations [4, 35, 41]. Hence, previous studies on ocean sunfish provided important insights into both horizontal and vertical movement dynamics. However, to understand habitat selection of a marine species it is important also to characterise the species' unused habitat. Robust models, including the approach we employed here, have not been used in any region where sunfish have been studied.

The aim of the present study, therefore, was to examine the movement and distribution patterns of satellitetracked ocean sunfish in the dynamic habitats of the north-east Atlantic. Here, sunfish behavioural patterns are less well known due to the limited duration and low sample sizes of previous studies. We estimated the probability of habitat use by ocean sunfish in the region by applying a logistic model (RSPF) to a combination of environmental variables. Briefly, sunfish movements were integrated with sea surface temperature (SST), SST gradients (fronts) and primary productivity [34, 42]. Finally, diel vertical migrations (DVMs) and changes in these patterns in relation to the thermal structure of the water column were also investigated. 


\section{Results}

From 2007 to 2013, 22 ocean sunfish were satellitetagged of which 18 (ranging in sizes from 0.60 to $1.40 \mathrm{~m}$ total length (TL); mean $0.92 \mathrm{~m}$, see Table 1) successfully reported sufficient data for movement tracking. Of these, eight individuals were tracked with pop-off archival satellite transmitter (PSAT) tags able to store depth, temperature and light-level data, providing both horizontal and vertical profiles. PSAT tags provided 9-43 geolocations per individual (mean 21), and tracking times varied between 6 and 120 days (mean 55 days). To estimate the spatial inaccuracy of the UKFsst-corrected tracks, both longitude $\left(\sigma_{\mathrm{x}}\right)$ and latitude $\left(\sigma_{\mathrm{y}}\right)$ standard deviations obtained from the parameterised geolocation errors were calculated for the pooled data [43]. The median errors associated with the estimated longitude and latitude corrections were $0.49^{\circ}\left[0.31^{\circ}-1.19^{\circ}\right]$ and $1.19^{\circ}\left[0.94^{\circ}-1.96^{\circ}\right]$, respectively. Thus, sunfish PSAT tracks had similar spatial errors to those found previously [e.g. 44, 45]. The remaining 10 fish were monitored continuously via Argos receivers on polar-orbiting satellites, with one tag (\#14) also recording depth and temperature data (see 'Methods' section). Of the obtained Argos locations, $60 \%$ had location classes (LC) 1-3 with reported error fields $<1.5 \mathrm{~km}$. Argos tagged fish were at liberty for 5-172 days (mean of
66 days), with the total number of geolocations per individual ranging from 18 up to 226 (mean 94). On average, the number of daily gaps (days) was 2.43, ranging from 1 up to 69 days, with only two tracks having gaps longer than 20 days (Table 2). Sunfish reported from 0.2 up to 10 positions per day (with an average of 1.6; see Table 3 for details). Tracking location numbers during the year were not consistent, with $28 \%$ of the retrieved positions corresponding to autumn; $29 \%$ to spring; $32 \%$ to summer and $11 \%$ to winter months, the season with the fewest sunfish positions. Moreover, on average, Argos tags remained attached for longer (96 days versus 58 and 55 from Argos-GPS and PSAT, respectively) and provided the largest average number of positions (103 against 91 Argos-GPS and 20 of PSAT). However, if weighted by days at liberty, Argos-GPS outperformed, in number of locations per tracked day ( 3), both PSAT (0.5) and Argos (1) tags.

\section{Distribution, horizontal movements and seasonality}

Overall, tracked sunfish displaced between 17 and $754 \mathrm{~km}$ from tagging locations (mean $317 \pm 225 \mathrm{~km}$ ), covering estimated total distances between 109 and $3351 \mathrm{~km}$ (mean $777 \pm 874 \mathrm{~km}$ ). Visual inspection of the trajectories revealed a wide dispersal pattern in the region

Table 1 Summary of all 22 sunfish tagged individuals in this study

\begin{tabular}{|c|c|c|c|c|c|c|c|c|c|}
\hline Type & Id & PTT & Tagging date & Pop-up date & Tagging location & Length (m) & Days liberty & Final date & Geolocations (N) \\
\hline PSAT & 1 & 66943 & 28/02/2007 & 29/04/2007 & Portugal & 0.70 & 43 & $12 / 04 / 2007$ & 17 \\
\hline PSAT & 2 & 66944 & 28/02/2007 & 29/05/2007 & Portugal & 0.70 & 91 & $30 / 05 / 2007$ & 18 \\
\hline PSAT & 3 & 40401 & 08/08/2007 & 06/11/2007 & Ireland & 0.64 & 54 & 01/10/2007 & 35 \\
\hline PSAT & 4 & 40398 & $12 / 08 / 2007$ & $11 / 10 / 2007$ & Ireland & 0.66 & 8 & 20/08/2007 & 11 \\
\hline GPS & 5 & 75760 & $14 / 05 / 2008$ & - & Portugal & 0.60 & 15 & 29/05/2008 & 23 \\
\hline GPS & 6 & 75761 & $14 / 05 / 2008$ & - & Portugal & 0.60 & 5 & 19/05/2008 & 50 \\
\hline PSAT & 7 & 86398 & 21/08/2008 & 18/01/2009 & Ireland & 0.63 & 47 & 07/10/2008 & 15 \\
\hline GPS & 8 & 75763 & 06/11/2008 & - & Portugal & 1.00 & 95 & 09/02/2009 & 142 \\
\hline GPS & 9 & 75762 & 18/05/2010 & - & Portugal & 0.97 & 172 & 06/11/2010 & 125 \\
\hline GPS & 10 & 99102 & $21 / 05 / 2010$ & - & Portugal & 1.00 & 9 & $30 / 05 / 2010$ & 18 \\
\hline PSAT & 11 & 107083 & 03/04/2012 & 01/08/2012 & Portugal & 0.80 & 41 & $14 / 05 / 2012$ & 12 \\
\hline PSAT & 12 & 107087 & 03/04/2012 & $01 / 08 / 2012$ & Portugal & 0.75 & 34 & 07/05/2012 & 9 \\
\hline SPOT & 13 & 66959 & $30 / 04 / 2012$ & - & Portugal & 0.93 & 64 & 03/07/2012 & 57 \\
\hline GPS & 14 & 15122 & 18/05/2012 & $18 / 05 / 2013$ & Portugal & 1.00 & 51 & 08/07/2012 & 59 \\
\hline SPOT & 15 & 66960 & 09/05/2013 & - & Portugal & 1.40 & 127 & 13/09//2013 & 148 \\
\hline PSAT & 16 & 107085 & $10 / 05 / 2013$ & 07/09/2013 & Portugal & 1.00 & 120 & 07/09/2013 & 43 \\
\hline GPS & 17 & 133671 & $14 / 10 / 2013$ & - & Portugal & 1.25 & 73 & 26/12/2013 & 89 \\
\hline GPS & 18 & 133672 & 19/10/2013 & - & Portugal & 1.15 & 47 & 05/12/2013 & 225 \\
\hline PSAT & - & 86397 & 14/05/2012 & 11/10/2012 & Portugal & 0.93 & - & DNR & - \\
\hline PSAT & - & 86408 & 03/05/2013 & $31 / 08 / 2013$ & Portugal & 0.85 & - & DNR & - \\
\hline SPOT & - & 40391 & 08/05/2013 & - & Portugal & 1.05 & - & PT & - \\
\hline PSAT & - & 85693 & 09/05/2013 & 06/09/2013 & Portugal & 1.35 & - & DNR & - \\
\hline
\end{tabular}

PT poor transmission, DNR did not report 
Table 2 Summary of all 18 sunfish tracked in terms of daily gaps

\begin{tabular}{|c|c|c|c|c|c|c|}
\hline \multirow[t]{2}{*}{ PTT } & \multicolumn{4}{|l|}{ GAPS } & \multirow[t]{2}{*}{ Min. Gap } & \multirow[t]{2}{*}{ Max. Gap } \\
\hline & $\geq 3 d$ & $\geq 5 \mathrm{~d}$ & $\geq 10 \mathrm{~d}$ & $\geq 20 d$ & & \\
\hline 66943 & 5 & 4 & 2 & 0 & 0 & 11 \\
\hline 66944 & 8 & 5 & 2 & 1 & 0 & $42^{* *}$ \\
\hline 40401 & 5 & 2 & 0 & 0 & 0 & 8 \\
\hline 40398 & 0 & 0 & 0 & 0 & 0 & 1 \\
\hline 75760 & 2 & 1 & 0 & 0 & 0 & 5 \\
\hline 75761 & 1 & 1 & 1 & 0 & 0 & 12 \\
\hline 86398 & 6 & 5 & 1 & 0 & 0 & 10 \\
\hline 75763 & 11 & 1 & 0 & 0 & 0 & 9 \\
\hline 75762 & 20 & 14 & 2 & 0 & 0 & 17 \\
\hline 99102 & 1 & 0 & 0 & 0 & 0 & 9 \\
\hline 107083 & 6 & 3 & 1 & 0 & 0 & 10 \\
\hline 107087 & 4 & 2 & 1 & 0 & 0 & 13 \\
\hline 66959 & 8 & 4 & 1 & 0 & 0 & 10 \\
\hline 15122 & 1 & 0 & 0 & 0 & 0 & 3 \\
\hline 66960 & 5 & 1 & 1 & 1 & 0 & $69^{*}$ \\
\hline 107085 & 14 & 8 & 2 & 0 & 0 & 11 \\
\hline 133671 & 10 & 2 & 1 & 0 & 0 & 10 \\
\hline 133672 & 3 & 0 & 0 & 0 & 0 & 4 \\
\hline
\end{tabular}

*Gaps exceeding 20 days were excluded by splitting tracks when gap in middle of track $(*)$ and removed completely when at beginning/end $(* *)$

Table 3 Summary of tag type performance

\begin{tabular}{lrrr}
\hline & Geolocations & Days liberty & Pos. per days liberty \\
\hline GPS & & & \\
Average & 91.38 & 58.38 & 2.86 \\
Max & 225.00 & 172.00 & 10.00 \\
Min & 18.00 & 5.00 & 0.73 \\
PSAT & & & \\
Average & 20.00 & 54.75 & 0.48 \\
Max & 43.00 & 120.00 & 1.38 \\
Min & 9.00 & 8.00 & 0.20 \\
SPOT & & & \\
Average & 102.50 & 95.50 & 1.03 \\
Max & 148.00 & 127.00 & 1.17 \\
Min & 57.00 & 64.00 & 0.89 \\
All & & & \\
Average & 60.89 & 60.89 & 1.60 \\
Max & 225.00 & 172.00 & 10.00 \\
Min & 9.00 & 5.00 & 0.20 \\
\hline
\end{tabular}

(Fig. 1a), which was related to season, with a northern latitudinal movement evident in spring-summer and southern movement into warmer waters of the Mediterranean or the north-west African coast observed during the colder months of winter (Fig. 1b). Furthermore, tagged fish in northern latitudes off Ireland all moved south in late summer and autumn months (Fig. 1b). After removing from the analysis the sunfish tagged off Ireland, that likely bias the seasonal latitudinal differences, we continued to detect significant differences in distribution by sunfish per season (Kruskal-Wallis $H=158.1$, $d f=3, p<0.001)$. Noticeably, summer and autumn were the seasons where the widest latitudinal range was observed (increased standard deviations: autumn mean $38.56^{\circ} \mathrm{N} \pm 3.205^{\circ}$; summer $38.72^{\circ} \mathrm{N} \pm 2.498^{\circ}$; spring $37.64^{\circ} \mathrm{N} \pm 2.094^{\circ}$; winter $35.02^{\circ} \mathrm{N} \pm 1.64^{\circ}$ ), reflecting an expanded north-south distribution. On the other hand, when accounting for the tagging bias (by dividing the number of locations retrieved per number of tags deployed in each $25-\mathrm{km}$ grid cell) we found that besides this wide distribution and the seasonality in movements, tracked sunfish also displayed high space use focused in three particular areas (Fig. 2a). Thus, after reducing the tagging bias, sunfish densities (estimated by the KDE on the normalised tracked positions) were still found predominantly in the Gulf of Cadiz region, north-west Iberian and the Alboran gyre.

Interestingly, the majority of sunfish tagged in spring off southern Portugal that did not display northward movements ( $n=6$ out of 8 ) were individuals smaller than the average TL of all tracked sunfish $(0.92 \mathrm{~m})$. Hence, a size-based analysis was completed for both the distance from tagging (Additional file 1: Figure S1A) and daily displacement (Additional file 1: Figure S1B). Individual analysis revealed that sunfish larger than the 


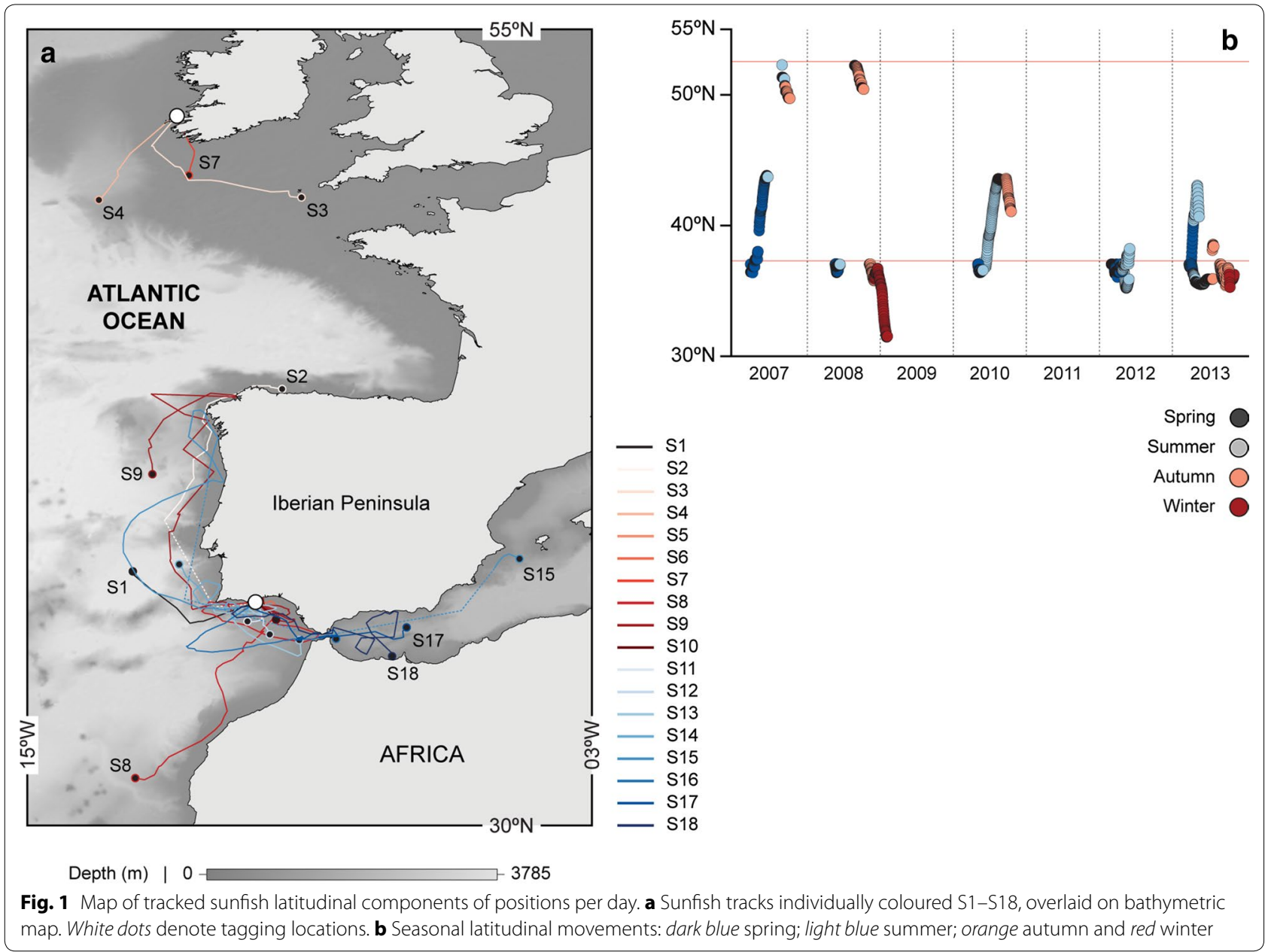

average TL of $0.92 \mathrm{~m}$ displayed significantly higher daily displacements $(12570 \pm 5920 \mathrm{~m})$ than smaller individuals $(8690 \pm 4320 \mathrm{~m})(t$-test: $t=5.55, d f=157$, $p<0.001)$. This generally greater daily distance travelled by larger individuals was also confirmed by the difference in the (cumulative) distance moved after tagging for the first 25 days, and when different tracking lengths with size and the initial limited movement period detected (in Additional file 1: Figure S1C) were both accounted for. Specifically, smaller individuals dispersed less overall $(93,200 \pm 38,500 \mathrm{~m})$ than larger sunfish $(128,600 \pm 57,200 \mathrm{~m})(t$ test: $t=-2.61, d f=23$, $p<0.05$, Additional file 1: Figure S1C). This difference was maintained when analysing distances for the period post-tagging after those 25 days and up to the maximum days-at-liberty of the small fish (65 days) ( $t$ test: $t=-3.05, d f=59, p<0.05)$. Hence, even though smaller fish were tracked for shorter periods of time, our results suggest larger sunfish displaced farther from the tagging location.

\section{Environmental integration of sunfish movements}

Plots of sunfish latitudinal movements along the mean coastal SST showed that tagged fish experienced approximately the same thermal range, independent of latitude, time within the year, and of year, with the exception of 2007. Overall, sunfish tracked outside the Mediterranean experienced a SST range from 13 to $23{ }^{\circ} \mathrm{C}$. This thermal envelope was found to be warmer for individuals that entered the Mediterranean $\left(15-27{ }^{\circ} \mathrm{C}\right.$, Figs. 3, 4). Sunfish also generally occupied waters of low productivity $\left(\leq 1 \mathrm{mg} / \mathrm{m}^{3}\right.$ chlorophyll $a$ concentration, where $\mathrm{Chl} a$ is a proxy for primary production), with sporadic encounters with productive 'hotspots' (from 5 to $16 \mathrm{mg}$ / $\mathrm{m}^{3}$ ). The integration of sunfish movements with Chl $a$ also showed that although not tracking higher productivity regions, sunfish seem to avoid oligotrophic 'coldspots' (Fig. 3). Lastly, especially during summer months and except for the years 2007-2008, sunfish movements appear linked to maxima in temperature gradients. The preference for these thermal discontinuities (fronts) or 


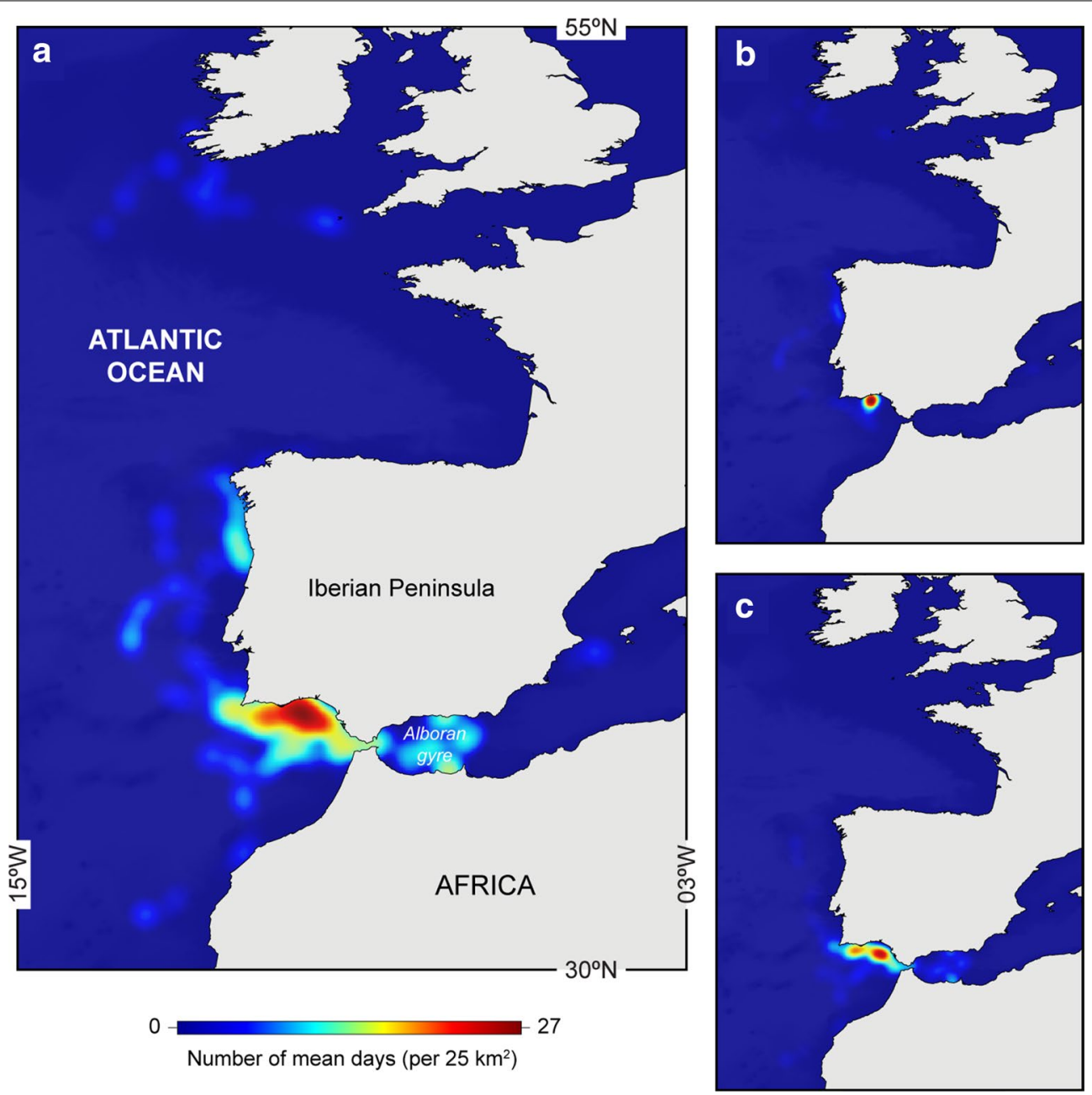

Fig. 2 Kernel density estimation (KDE) of sunfish occurrence. a Overall sunfish tracked, $\mathbf{b}$ KDE of individuals of total length (TL) below the average $0.92 \mathrm{~m}$, c larger sunfish KDE

the vicinity of these was clearer in the sunfish movements made towards the Mediterranean (Fig. 3). Thus, overall movements appear to generally 'track' a strict thermal envelope of SST and follow seasonally persistent thermal gradients, while avoiding oligotrophic regions.

\section{Sunfish habitat preferences}

To investigate the influence of the environment on sunfish movements, the habitat selected by tracked fish was compared to that available in non-occupied regions, thus providing predictive maps of sunfish occurrence in areas where they were not tracked. Overall, the most parsimonious RSPF model included all four variables (SST, SST gradients, SST anomalies and chlorophyll $a$ concentration) (Additional file 2: Table S1 and Fig. 5). Model was validated by the GOF (Hosmer and Lemeshow) $\chi^{2}=12.22, d f=8, p=0.142$. This model explained $33 \%$ of the sunfish habitat-use probabilities, and variables were selected based on Akaike weights [46] which specified the importance of each parameter for the model. Briefly, using the cross-validation property of AIC under repeated sampling, the full model has greater chances of being selected ( $45 \%$ of the time), whereas a model without chlorophyll $a$ was ranked best $27 \%$ of the time and a model without SST anomalies would better inform sunfish habitat selection for $28 \%$ of the times. Importantly, models with no SST or SST gradients had negligible probabilities of explaining the fish distribution (Additional file 3: Table S2). Therefore, sunfish habitat use was found to be strongly influenced by temperature, with fish avoiding higher temperatures, preferring areas with sharp SST gradients and positive anomaly with regard to previous years, whereas chlorophyll $a$ had no significance for the fish overall habitat selection (Additional file 3: Table S2).

Summer and autumn seasonal models were significantly influenced by frontal regions approximated by SST 


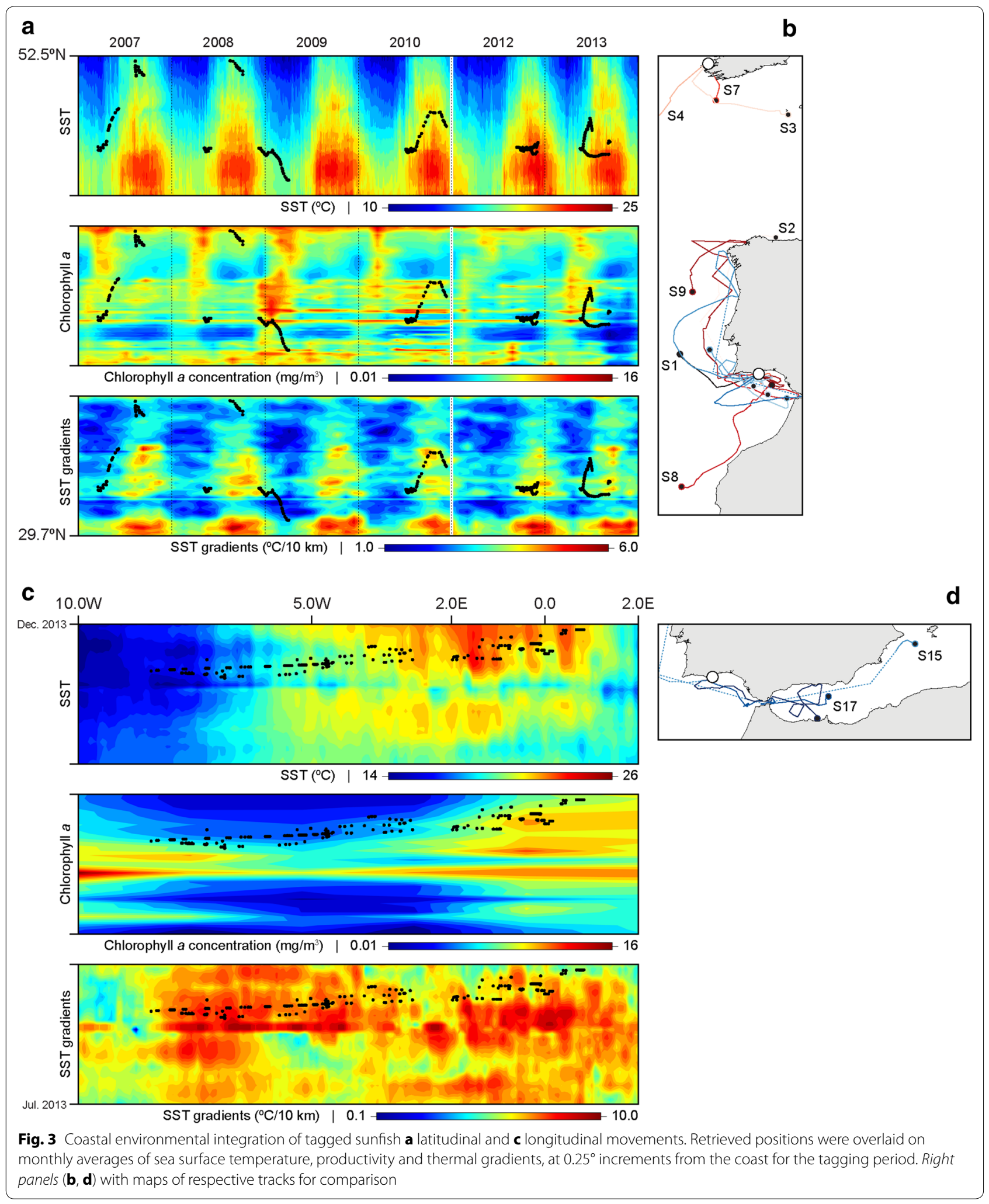




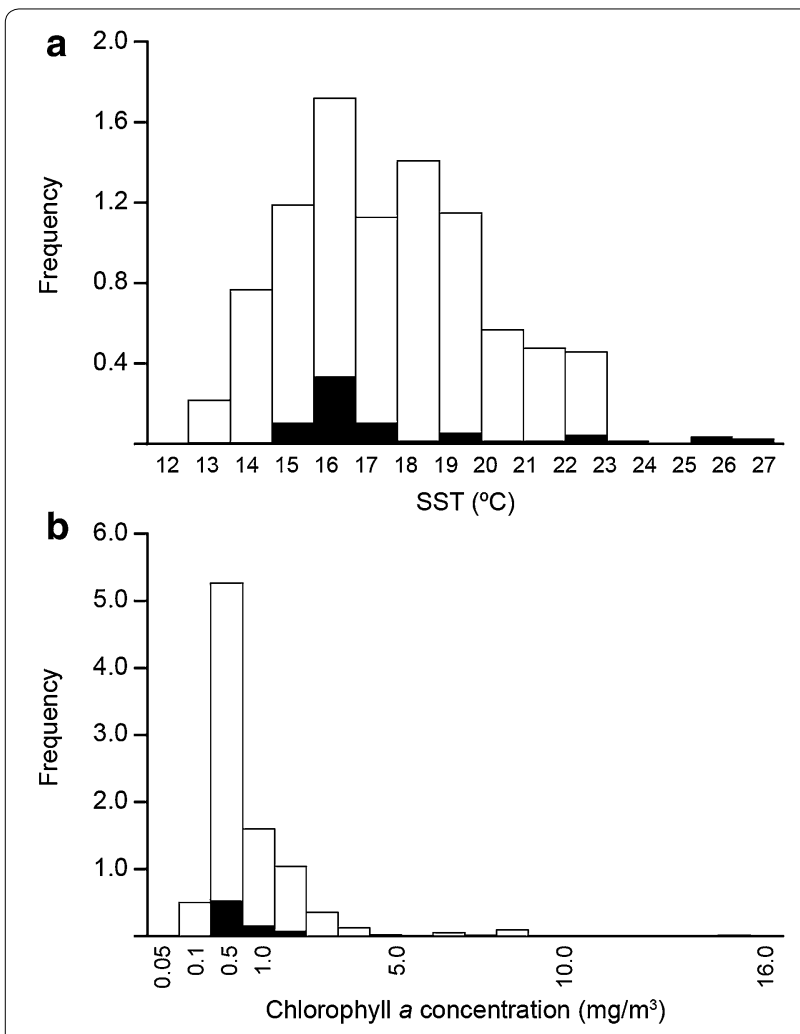

Fig. 4 Encountered SST and chlorophyll $a$ histograms for all sunfish tracked locations. Black denotes tracks when in the Mediterranean (\#14,\#17-18) and white all the remainders

gradients, which was confirmed by the low wAIC when this feature is removed from the full models. With regard to chlorophyll $a$, although not significant, the negative effect was maintained in summer, spring and autumn months, while SST negatively influenced sunfish habitat during summer and spring months. Despite being a significant driver of sunfish distribution in the general model, SST anomalies did not significantly influence the fish habitat selection seasonally. In winter, no variable was found to influence sunfish habitat directly (Additional file 4: Table S3). Ultimately, the seasonal predictive maps of sunfish habitat not only highlighted the northsouth migratory pattern across much broader scales than were visited by satellite-tracked fish (Fig. 5b-e), but also identified areas likely to support high sunfish densities, even though none were tracked in those areas. For example, Fig. $5 \mathrm{c}$ indicates a high probability of sunfish habitat selection off the south-west peninsula of the UK which in previous studies has been shown to have high sunfish abundance in summer months [42, 47]. This indicates that satellite-track-informed environmental modelling can yield species seasonal distribution maps that show heterogeneities beyond the data used to parameterise the models (see Additional file 5: Table S4 for GOF results).

\section{Diving profiles of sunfish}

PSAT-tracked sunfish exhibited an extended vertical distribution, from the surface to a maximum depth of $704 \mathrm{~m}$ $(480 \pm 125 \mathrm{~m})$. Analysis of the time at depth (TAD) revealed that overall, sunfish spent $\sim 25 \%$ of the time in the top $10 \mathrm{~m}$ layer; $53 \%$ between 10 and $100 \mathrm{~m}$ depth; and $12 \%$ in depths exceeding $200 \mathrm{~m}$, Additional file 6 : Figure S2. In relation to individual size, we found that larger sunfish tended to spend significantly more time in deeper layers (below $250 \mathrm{~m}$ ) (Spearman rank correlation: $\left.r_{\mathrm{s}}=0.71, p=0.03\right)$. Furthermore, we also found a positive correlation between the vertical extent of the water column used (maximum-minimum depth) and the total length of tagged individuals (Spearman rank correlation: $\left.r_{\mathrm{s}}=0.710, p<0.05\right)$.

\section{Behavioural shifts in depth occupancy}

A split moving window (SMW) analysis was used to detect significant discontinuities in depth use along individual diving profiles, which were then divided at these discontinuities into 19 sections that likely represent bouts of differing behaviour. All sections' TADs were then examined to identify periods of either normal diel vertical migration (nDVM, where the animal is in deeper water during the day and shallower at night) or reverse DVM (rDVM, deep during the night, shallower during the day). Of the 19 sections, 10 exhibited diel changing movements, with nDVM $42 \%$ of the time and rDVM $11 \%$ of the time (Fig. 6a, b). To our knowledge, this is the first time rDVM has been observed in sunfish. The remaining nine sections showed no difference in diel movements. Overall, $32 \%$ of the time sunfish showed a surface-oriented pattern, without deep incursions (Fig. 6c), whereas for the remaining $15 \%$ of the time it was not possible to assign a specific behaviour as the fish exhibited similar depth occupancy both day and night, but were not restricted to surface layers (Table 4). Furthermore, no correlation between sunfish diel behavioural mode (normal, reverse or surface oriented) and a specific geographical region was detected. Examples of the three diel diving patterns are given in Fig. 6. Variability of temperature with depth, retrieved from the PDT data for each summary bin, revealed water column stratification occupied by the sunfish. We found sunfish occupied well-mixed waters (53\%), frontal regions $(32 \%)$ and stratified waters $(15 \%$ of the time), but there was no strict link between diving profile and water column stratification (Table 4). Lastly, diel temperature occupancy was analysed for the individual sections determined by the SMW analysis and for each of the behavioural sections no significant differences were found in temperature use (K-S test, $p>0.05$, respectively). 

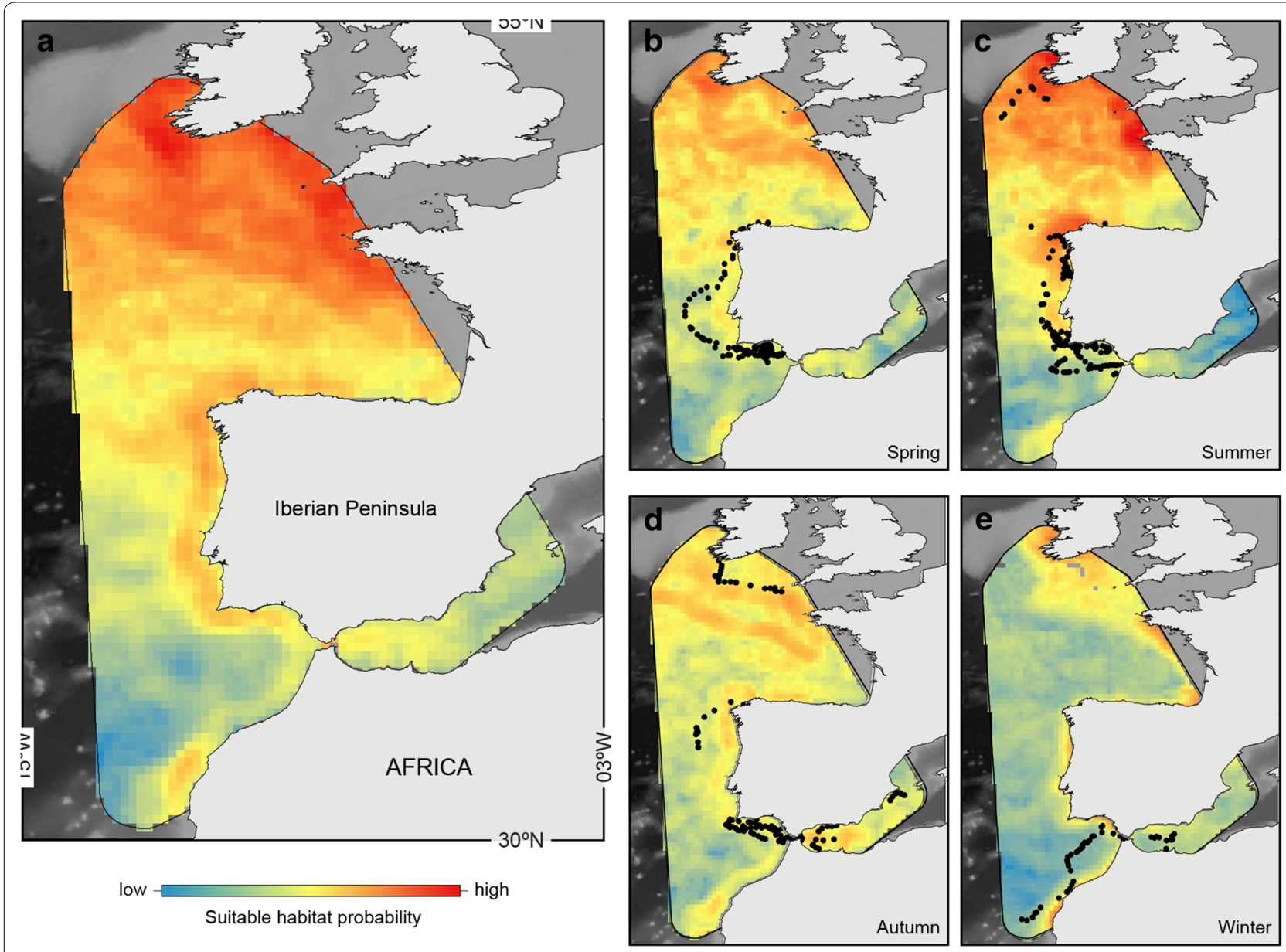

Fig. 5 RSPF model predictions for sunfish distribution in the north-east Atlantic. a Overall predictive distribution, for the tagging years and as a direct response to averaged sea surface temperatures, fronts and chlorophyll $a ; \mathbf{b}$ seasonal predictive models for sunfish distribution, spring; c summer; d autumn and e winter. Black dots denote sunfish positions in each season

\section{Discussion}

Movements of ocean sunfish in the north-east Atlantic were observed from 18 satellite-tracked individuals in this study, and we found significant size-based differences in the average daily movement distances and in the degree of apparent fidelity to an area. Furthermore, we detected a seasonal trend in the sunfish dispersal, with individuals tagged in spring moving northwards, whereas in winter a southern latitudinal preference was evident. We also detected focused residency areas, such as the Gulf of Cadiz, the north-west Iberian Peninsula and the Alboran gyre. Importantly, these focal areas were identified after accounting for potential spatial bias of the tagging site on the number of satellite locations. Overall, sunfish movements in relation to changing environments were consistent with sunfish following thermal gradients (preferentially during summer months) and avoiding oligotrophic regions. Modelling sunfish habitat use, through RSPFs, confirmed that SST, thermal discontinuities and Chl $a$ statistically influence the sunfish probability of occurrence. From the analysis of diving profiles of nine individuals $(\leq 1.00 \mathrm{~m})$, different vertical behaviours were found from nDVM, rDVM, surface-oriented and an irregular profile with no diel patterns being evident. In addition, we also recorded shifts in diving behaviour with no apparent link with water column stratification. Taken together, these results, despite relatively few individuals, confirm satellite-based biotelemetry and oceanography as a powerful tool, providing valuable new insights into shifting habitat selection by ocean sunfish.

\section{Distribution, horizontal movements and seasonality: environmental integration of sunfish movements}

In this study, movement patterns of tracked sunfish provided further support that this species moves to higher latitudes in warmer months of late spring-summer in the north-east Atlantic Ocean [34], similar to the pattern 


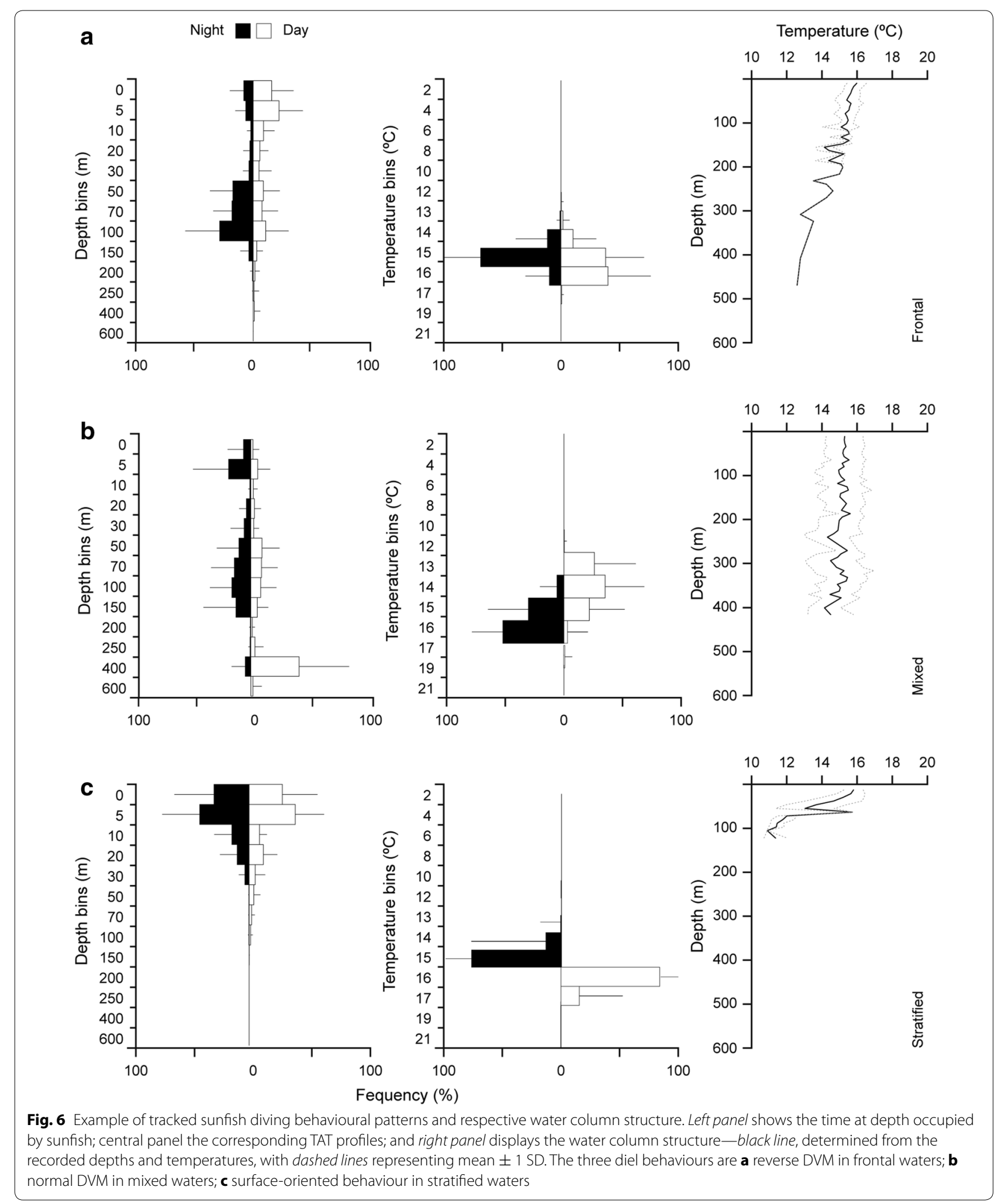


Table 4 Summary of the diving profiles patterns found for sunfish PSAT tracked in this study and in relation to the water column structure ( $n=19$ sections were distinguished)

\begin{tabular}{lllll}
\hline & nDVM (\%) & rDVM (\%) & Other (\%) & Surface (\%) \\
\hline Stratified & 12.5 & 0.0 & 0.0 & 33.3 \\
Frontal & 37.5 & 50.0 & 33.3 & 16.7 \\
Mixed & 50.0 & 50.0 & 66.7 & 50.0 \\
\%Total & 42 & 11 & 15 & 32 \\
\hline
\end{tabular}

found in the north-western Atlantic [37]. These northsouth movements have been linked to the ability of the species to cope with seasonal variations in temperature [34] and were also observed in the Pacific Ocean. Sunfish satellite-tagged off Japan moved northward as waters warm [36], and in the eastern Pacific, a higher seasonal occurrence with the warming waters off California suggested a migratory activity also linked to SST [33]. Furthermore, other marine predators, such as the blue shark, showed the same northward summer movements in the north-east Atlantic that are related to SST variations [8], and the long-term satellite tracking of both the leatherback (Dermochelys coriacea) [48] and loggerhead turtles [15] also conform to this migratory pattern of higher latitudinal occurrence during summer periods. Similar to the leatherback turtle, sunfish also feed on gelatinous zooplankton, among other prey items [49], a feeding preference which may underpin the northwards movement as waters warm and zooplankton blooms in high latitudes [38]. These zooplankton blooms have been documented to attract higher-trophic level species such as sharks, bony fish, turtles and seabirds [e.g. 16, 50, 51]. Our results provide examples of individual sunfish northward movements apparently 'riding a wave' of optimal temperature envelope (increasing in summer) at higher latitudes (and SST gradients; Fig. 3a). However, the relationship between northward extent and maximum primary productivity was less clear by comparison. The subsequent southward movements with local decreased temperatures, together with the southward movements observed in sunfish tagged in Ireland [38], suggest a thermal niche for sunfish that does not extend to the lower temperatures characteristic of higher latitudes in winter, with sunfish tracked in this study not occupying waters with SST lower than $9{ }^{\circ} \mathrm{C}$. Interestingly, a clear sizerelated residency versus larger-scale movements was found in the present study, with smaller sunfish remaining closer to the tagging region as opposed to larger individuals, which undertook wider displacements into more oceanic waters.

Space-use analysis indicated site fidelity to areas in the Gulf of Cadiz (GoC), the north-east Iberian Peninsula and the Alboran gyre. These patterns of temporal residency (after reducing tagging site bias) were in regions of seasonal enhanced productivity. The area off western Iberia is characterised by an equatorward upwelling jet during the upwelling season from May to October. This upwelling-driven frontal region is an important 'hotspot' for marine biodiversity [7, 34, 52], characterised by elevated bioaggregation, where the interface between offshore warmer oligotrophic waters with cool, nutrientrich upwelled water has been shown to attract highertrophic level foragers [e.g. 7, 53]. Sunfish in this study were also found to spend longer periods in the vicinity of the Alboran gyre, within the Alboran Sea, which is known as the most productive area in the Mediterranean Sea [54]. Furthermore, the surface circulation in the GoC is directly linked to the north-eastern part of the North Atlantic subtropical gyre. A colder, open-ocean inflow in the region contrasts with the continental shelf warmer waters forming a frontal region [55]. Thus, although subject to seasonal and interannual fluctuations [56], this frontal area may be a major driver for the persistent occurrence of the smaller ocean sunfish we tracked in the region, mainly tagged during late spring and summer seasons. The GoC area is a well-known spawning and development region for other pelagic animals, including the European anchovy (Engraulis encrasicolus) [57], oceanic cephalopod paralarvae [58] and crustacean decapod species such as the rose shrimp (Parapenaeus longirostris) [59]. Therefore, the elevated production in the coastal region of the $\mathrm{GoC}$ may be linked with a nursery area for younger stages of sunfish, by providing enhanced feeding opportunities that can support fast growth rates.

\section{Sunfish habitat preferences}

Although several studies have satellite-tracked the horizontal movements of ocean sunfish [35-37], none has explored, in an analytical framework, the environmental factors driving this species' distribution and habitat selection patterns. Here, we characterised the associations between sunfish and their immediate environment, using a presence versus available habitat design [28]. Our model of habitat selection revealed a spatial occupancy in the north-east Atlantic and in relation to water temperatures conforming to previous results in the region [34, 35] and elsewhere [36, 37]. Sunfish movements were related to a thermal envelope consistent with an 'escape' from maximum temperatures in the southern region in warmer months of spring and summer $\left(\geq 25{ }^{\circ} \mathrm{C}\right.$, see Fig. 3a). Likewise, the preference for frontal regions, also apparent in our model, has been described for other predators in the same geographical region as this study, linked to increased abundance of prey and thus, enhanced foraging opportunities $[9,51$, 
60]. Furthermore, our results confirm previous observations in the north-east Atlantic [42] and more recently in the Pacific, where sunfish were associated with upwelling frontal regions [61]. Animal movements are expected to be driven by environmental suitability to satisfy the species intrinsic demands, such as feeding, which in turn is motivated by the abundance of prey [e.g. 19, 62]. Hence, despite not being significant the negative influence of chlorophyll $a$ in the overall sunfish habitat selection is a somewhat counterintuitive result, given the expectation of increased occurrence of predators in highly productive regions. One possible explanation for this is that sunfish do not track primary productivity directly, but rather move northwards as preferred thermal conditions extend latitudinally and coincide with zooplankton blooms that then occur seasonally. Importantly, with the exception of a few months, a temporal mismatch between primary production and zooplankton was detected in the monthly patterns of phytoplankton and total copepod abundances (zooplankton) for the Goban Spur region, North Atlantic [63]. Lastly, the modest positive influence of SST anomaly in the overall habitat selection of sunfish may reflect longer-term trends in migratory patterns of the species.

Sunfish seasonal occupancy in the area predicted by the logistic RSPF is consistent with the inference from our satellite-tracked movements, thus showing the utility of the model for making accurate broad-scale sunfish habitat-use estimates. The modelled habitat distribution also identified probable high-use areas not visited by tracked sunfish. For example, the sunfish 'hotspot' predicted off south-west England (Fig. 5c) has been validated by ship and aerial surveys with high sunfish abundances reported in previous studies $[42,47]$. This emphasises the value of understanding how sunfish use habitats at the population level and across their distributional range. Understanding the relation between sunfish and the environment within a model allows the determination of potential habitats, ultimately improving our ability to predict future shifts in the population distribution due to environmental changes [64].

In this study, the seasonal sunfish movement towards northern latitudes during summer was correctly estimated by the model (Fig. 5c) and may be explained by the avoidance of high temperatures at southern latitudes during warmer months. During summer, the increased water temperatures in the region might drive sunfish northward, with the fish possibly moving away from excessive temperatures while also tracking the intense frontal region off western Iberia, which in summer is characterised by a strong upwelling phenomena approximated by significant positive SST gradients in the model. In winter, the model correctly estimated the southern movements of sunfish (Fig. 5e), which conform to the suggested thermal tolerance for this species (above the minimum of $9.9{ }^{\circ} \mathrm{C}$ ) [35]. Similarly, the identified southern movement of sunfish during cooler months, either to warmer Mediterranean waters or along the north-west African upwelling region, revealed a good approximation of our model to the broad-scale distribution of sunfish in the region. The negative influence of primary productivity found in our overall model was maintained during summer, spring and autumn months. Hence, the preference for other environmental conditions, such as the strong thermal gradients representing frontal regions, may be of more importance for the species distribution than primary productivity per se. Importantly, sunfish likely feed on organisms that consume primary productivity (e.g. phytoplankton), and thus, the negative chlorophyll $a$ estimate likely reflects the presence of sunfish prey.

In summary, the overall predictive map of sunfish habitat selection generated probable habitats for sunfish across much broader scales than was possible with the obtained tracking locations reported in this study, but which seem consistent with incidental reports of sunfish hotspots $[42,47]$. These results with relatively few individuals confirm the usefulness of the integration of satellite-based biotelemetry with oceanography in improving our knowledge into shifting habitat selection by a marine predator. The methodology employed to account for the different tracking systems (Argos and light-level) spatial inaccuracies ensured the incorporation of a more complete tracking data set covering all seasonal periods, and thus informed the spatial dynamics and environment-use of the ocean sunfish.

\section{Sunfish diving profiles}

Vertical diving records from ocean sunfish revealed a consistent broad range of depths in all nine individuals for which there was depth data, with sunfish occupying the water column from the surface to $704 \mathrm{~m}$ $(480 \pm 125 \mathrm{~m})$. This vertical range varied with tracked individuals' size, even though they did not exceed $1.00 \mathrm{~m} \mathrm{TL}$. The larger individuals displayed significantly extended depth amplitudes and increased time in deeper layers $(>250 \mathrm{~m})$, which may reflect sunfish tracking vertically migrating prey [34]. Importantly, current shear will disperse the scents and tastes [65] and sunfish will likely have a greater chance of encountering a prey/food trail by searching vertically through the layers. Moreover, the recent fine-scale tracking of sunfish off Japan leads the authors to suggest that large body mass enhances the ability of the species to cope with vertical temperature gradients [66]. Our results of greater time in deep water for larger fish are consistent with this observation.

Overall, our analysis confirmed the predominance of an overall nDVM behaviour in sunfish [33, 35, 36]. 
However, several other patterns were detected and our study suggests that in the north-east Atlantic sunfish of smaller sizes $(\leq 1.00 \mathrm{~m})$ exhibit different diel depth preferences, with the first indication of a reverse DVM being observed. Sunfish are known for significant deep dives, and it was suggested that time spent at the surface would be a mechanism to compensate for the heat lost at depth in colder waters [33]. This was recently confirmed in a study with sunfish tagged off Japan, where the authors described a thermoregulatory behaviour occurring at a scale of several minutes [66]. In our study, however, the coarse resolution of our depth data makes a similar investigation impossible. Further sunfish tracks, providing high-resolution dive profiles (minutes), would be required to identify such finer-scale behaviours in this region [66]. Importantly, our results show that the depths sunfish occupy during the day and night do not vary geographically, with all vertical behavioural patterns (at different times) occurring in all areas. Strikingly, SMW identified significant differences in sunfish behaviours with no linkage to a specific water column structure. All four behavioural modes (nDVM, rDVM, surface oriented and other) were found in both frontal and well-mixed waters, and when in stratified waters sunfish performed either nDVM or surface-oriented patterns (Table 4). Hence, although significant changes in the vertical behaviour of sunfish were found, there was no clear link between fish behaviour and the thermal structure of the water column.

Sunfish DVM has also been proposed to be a foraging strategy $[33,35,36]$, with fish potentially tracking DVM of gelatinous prey in the water column [67]. Similarly, the archival tracking of the plankton-feeding basking shark together with zooplankton monitoring with nets and echosounders demonstrated that this shark undertakes rDVM in frontal habitats that are dominated by Calanus copepods exhibiting rDVM to avoid predatory invertebrates (chaetognaths, arrow worms) [10, 68], whereas in stratified waters they exhibit nDVM [10]. In this study, sunfish rDVM was performed equally when in frontal regions and well-mixed waters, whereas $\mathrm{nDVM}$ and surface-oriented behaviours occurred in all three water column structure types. Another predator of gelatinous plankton, the leatherback turtle, was found to display daily deep diving in some areas, and shallow diving with no diel patterns in others, probably mirroring prey behaviour [19]. High-resolution vertical profiles of jellyfish, a known prey for sunfish [66], revealed, however, the lack of a systematic day-night shift in depth [67]. Furthermore, stable isotope analysis suggested an ontogenetic shift in the dietary habits of sunfish both in the Mediterranean Sea and off Japan [69, 70], with smaller sunfish focusing within coastal food webs, while larger individuals mainly feeding on vertically migrating prey in deeper waters. Here, sunfish tracked with PSAT standard depth tags were small $(\leq 1.00 \mathrm{~m})$, and for individuals this size, prey preferences are less clear. Yet, it seems likely that a combination of both benthic crustaceans and gelatinous, vertically migrating species may be consumed by fish this size $[69,70]$. Hence, the highly variable diving patterns recorded in our study confirm these assumptions, further supporting the broad feeding habits of smaller sunfish. Altogether, these results suggest widespread behavioural variability in the diving patterns of ocean sunfish, similar to several other generalist predators, and probably in response to diverse prey distributions and/or behaviours.

\section{Conservation and management implications}

Understanding how environmental factors influence vertical distribution patterns is important for marine resource management and conservation. Despite the low commercial importance of sunfish for fisheries worldwide, increased bycatch of this species [49] urges a better knowledge of this species' spatial dynamics. Sunfish are a common incidental capture in different fishing fleets operating worldwide [see review in 49], and quite often this species is observed in longlining operations at the North Atlantic (G.M personal observation). In our study, sunfish were found associated with frontal areas, which are known to be intensively selected by fishing operations in the north-east Atlantic [9]. Analysis of the space use of longliner fleets operating in the region (Additional file 7: Figure S3) suggests an overall high vulnerability of sunfish to longlining activities. Additionally, the increased time sunfish spent between 0 and $200 \mathrm{~m}$ in this study raises concerns, as this is the depth range across which longliner's hooks are deployed, depending on both target species and the wind or current strength [71]. Therefore, a better understanding of a marine species space use as presented here is crucial for important conservation measures, such as the implementation of high seas marine protected areas (MPAs) for large pelagic predators. Hence, further integration of this spatial usage analysis with fisheries activities is urgently needed.

\section{Conclusions}

In summary, by satellite-tracking 18 individuals in the northeast Atlantic our study has revealed a broad range of vertical and horizontal movement patterns in sunfish. We identified seasonal movements, with sunfish favouring northern latitudes in warmer months, whereas in colder periods the species tended to reside at more southern locations. Despite these clear seasonal patterns, longer tag attachments providing yearly recordings for this species are desirable to confirm migratory behaviour. In addition, we documented 
spatial focal residency in highly productive regions, with track-estimated habitat selection being driven by sea surface temperature and highly influenced by thermal gradients. Moreover, four different diving behaviours were recorded indicating similarities between sunfish and other marine vertebrates. Observed patterns are probably associated with prey behavioural differences as no geographical or water column stratification dependencies were found. Moreover, even though no adult sunfish [larger than $1.40 \mathrm{~m}$; 72] were tagged in this study, we have identified a size-specific pattern in both horizontal and vertical movements. We found larger sunfish travelled longer distances while exploring increased depth amplitudes, where they stayed for longer, compared to smaller individuals. From previous studies, sunfish was found to have different trophic associations in relation to fish size $[69,70]$ and our results are consistent with divergent prey preferences and feeding strategies.

\section{Methods}

\section{Tagging}

Between February 2007 and October 2013, a total of 22 ocean sunfish were fitted with three different electronic tag types: pop-off satellite archival transmitters, PSATs (PAT-MK10, Wildlife Computers); Argos Platform Terminal Transmitter, PTT (SPOT5, Wildlife Computers); and an integrated Fastloc ${ }^{\mathrm{TM}}$ global positioning system, GPS tag (Wildlife Computers and Sirtrack Ltd). The majority of sunfish were tagged in a set-net targeting tuna, off Olhão, southern Portugal, where, on a daily basis, a large number of healthy individuals are passively captured and released. In addition, three individuals were tagged off Ireland with PSAT tags, by approaching slowly in a rigid inflatable boat and throwing a cast net over the fish which was then handcaptured. Tethered tags were placed at the muscle near the base of the dorsal fin prior to 2013, after which the tag was attached to the basis of the caudal fin. A total of three SPOT5 tags were attached to sunfish, using stainless steel bolts, washers and nuts provided by the manufacturer. Tags were placed near the tip of the dorsal fin to maximise chances of transmission when the animal was near the surface. Fastloc-GPS tags mounted in a cylindrical housing were attached externally to eight fish, via a $1.5-\mathrm{m}$ tether of 200-lb test monofilament line and alloy crimps. The remaining 11 individuals were tagged with PSATs (Mk10) tags secured externally to the base of the dorsal fin, using a 0.5 monofilament line of $\sim 0.30 \mathrm{~m}$ and alloy crimps. Of these 22, four tags did not report and/or reported very few records so locations were not considered in the analysis.

\section{Track processing}

Argos positions were obtained for two SPOT5 tracked fish and eight Argos-linked Fastloc ${ }^{\mathrm{TM}}$ GPS tags and were calculated via the Doppler shift of consecutive transmissions via Argos satellites (CLS Argos). This system provides positions with variable accuracy from $150 \mathrm{~m}$ (LC 3) up to $10 \mathrm{~km}$ (LC B, [73]). To improve location estimates, biologically implausible locations were first removed using a $5 \mathrm{~ms}^{-1}$ point-to-point swim speed filter, together with any points that fell on land $(n=3)$.

Light intensity recorded by the PSAT tags was processed using the manufacturer's software (WC-GPE, global position estimator program suite) to determine midday or midnight for longitude estimation, and day length for latitudes. An inbuilt state-space model, the unscented Kalman filter-UKFsst, [74], was then applied to the raw location estimates to correct anomalous positions, using SST data from Reynolds at $0.25^{\circ}$ NOAA Optimum Interpolation. Thus, most probable tracks were obtained after removing improbable locations $(n=14)$.

Given the irregular temporal scale of both Argos and light-level data, a Kalman filter was applied to the corrected tracks, implemented in the 'crawl' package in $\mathrm{R}$ software, interpolating all tracks into daily positions. Argos positions were parameterised with the constant (K) error model parameters for longitude and latitude implemented in the crawl package [75]. UKFsst geolocations were parameterised with standard deviation (SD) constants (K) which produced the smallest mean deviation from concurrent Argos positions as described by Sippel et al. [44]. To avoid inaccurate interpolations, gaps exceeding 20 days were removed and respective tracks were split into sections [6], so no extra bias due to interpolating across large gaps was added. Tracks were then plotted using ArcGIS geographical information system (ESRI Inc, CA, USA), where home range ( $95 \%$ minimum convex polygon-MCP) was estimated. Furthermore, to reduce deployment area biases, mean days per grid cell was calculated as the ratio between the total number of positions within each cell and the number of respective tags [7]. Spatial usage from all individuals was then inspected by means of a kernel density estimator (KDE) using this weighted tracks. This way, position data set density is normalised by the tracking effort per cell, and hence, we objectively quantified sunfish high-use regions [7].

\section{Distribution per season and sunfish size}

Sunfish distribution was first inspected in relation to season and categorised as follows: winter (December-February); spring (March-May); summer (June-August) and autumn (September-November), with latitudinal occupancy of fish being explored regarding the time of year. A single-factor analysis of variance on ranks (nonparametric Kruskal-Wallis test) examined seasonal movement differences. As fish tagged in Ireland $(n=3)$ may bias the variability found in occupied latitudes, these data sets were removed from this seasonal analysis. Since different size 
fish were tracked in this study, we also investigated the possible link of detected movement patterns in relation to the average TL of $0.92 \mathrm{~m}$. Thus, individual daily distances and cumulative displacements were examined per size class (smaller and larger than $0.92 \mathrm{~m}$ ). Accounting for sizedependent track lengths and the apparent-limited movement found after tagging (Additional file 1: Figure S1C), both small and large sunfish daily cumulative displacements were examined for two periods: first 25 days-initial limited movement period detected; and post- 25 days up to the maximum tracking period of small sunfish.

\section{Environmental integration and modelling of detected movements}

To integrate sunfish movements in the encountered environment, the following environmental features were analysed: sea surface temperature (SST-from AVHRR V2 NOAA Optimum Interpolation 1/4 Degree Daily Sea Surface Temperature Analysis); SST anomalies with reference to previous years for temporal variability detection; SST gradients (thermal gradients measured as the difference from the surrounding SST pixels when compared to the central, occupied pixel) and chlorophyll $a$ concentration $\left(\mathrm{mg} / \mathrm{m}^{3}\right)$ for case 1 water from MODIS Moderate Resolution Imaging Spectrometer, GlobColour level-3 Product 1/4 Degree Weekly), as a proxy for primary production. Large-scale PSAT tracking system-associated errors were accounted for in the environmental extraction by calculating an average of the surrounding 5 pixels $\left(5 \times 5\right.$ matrix) for light-level locations (totalling $125 \mathrm{~km}^{2}$ and encompassing the PSAT error of $\sim 111 \mathrm{~km}[44,45])$. Afterwards, latitudinal movements of sunfish were compared to temperature (SST), frontal regions (SST gradients) and productivity ( $\mathrm{Chl} a$ ) along the fish's occupied region. Briefly, we calculated average SST, Chl $a$ and SST steep gradients for each latitude from 30 to $52^{\circ} \mathrm{N}$ in $0.25^{\circ}$ latitudinal steps and longitudinally for the area between -12 and $-2^{\circ} \mathrm{W}$ at the same incremental steps.

To model sunfish distribution in relation to the environment, we used a resource selection probability function (logistic RSPF) with maximum likelihood estimates and nonparametric bootstrap standard errors. To account for the spatial error around real individual geolocations, we randomly resampled the sunfish location 30 times within respective tag-specific longitudinal and latitudinal Gaussian errors [0.12 ${ }^{\circ}$ for Argos following 76] [and $1.08^{\circ}$ latitude and $0.53^{\circ}$ longitude in PSAT according to 44]. Thus, averaged environmental features from the resampled locations were assigned to each of the original corrected locations and only records with complete environmental description were maintained in the analysis. For each tracked sunfish, both turning angles and step lengths were calculated and frequency distributions delineated. Based on this step, a total of 100 null tracks (pseudo absences) per real trajectory were simulated. The initial position for these null tracks was randomly set within the actual tagging location error field while accounting for each system localisation uncertainty, as stated above [44, 76]; the initial turning angle was derived from a uniform distribution. Discrete steps and turning angles were then drawn from each individual real steplength and turning angles distributions, with the former limited by the actual number of individual steps for each tracked fish. In between each position, erroneous locations on land were identified and replaced by new step-length and angle and the resultant simulated tracks were constrained to the $95 \%$ home range MCP of tracked fish. To reduce the spatial autocorrelation between positions, only consecutive positions separated by $1 / 3^{\circ}$ were maintained and used in the model computation. This step was performed in both real and simulated tracks, and the $1 / 3^{\circ}$ was chosen to encompass the resolution of the environmental features selected.

RSPF model included SST, Chl $a$, gradients of SST and anomalies of SST, all treated as explained above. Analysis of colinearity among the selected variables was performed using Spearman rank correlation matrix, but no significant correlation was found for the set of environmental features extracted. Best model was obtained by using Akaike values (AIC) after removing each variable at a time, using ' $q p c R$ ' package in $\mathrm{R}$, and included all variables given the absence of a null Akaike weight (wAIC) associated with each reduced model. Final models were then run as follows: (1) a general modelling of the overall sunfish habitat selection was performed using all candidate variables and sunfish records; (2) seasonal models were run by splitting the record data set into each season. Finally, both overall and seasonal model probabilities were mapped for visual inspection. Following [46], variables' significance was inspected by comparing the performance of different models from which each variable was removed sequentially, using the cross-validation property of AIC under repeated sampling (wAIC). Model overall deviance was then calculated as the ratio between the difference between the full model and the null model deviances (no variables incorporated) with this null deviance [77]. Model validation (Hosmer and Lemeshow goodness of fit-GOF) was assessed for all generated frameworks.

\section{Sunfish diving behaviour}

Vertical profiles were derived from PSAT and one Fastloc-GPS ${ }^{\text {TM }}$ satellite relayed depth data, i.e. summaries of depth and temperature utilisation binned at 4 (PSAT) or $6 \mathrm{~h}$ (Fastloc-GPS ${ }^{\mathrm{TM}}$ ), depending on the tag programming set-up. This data set was processed using the manufacturer's software and then analysed by means of a customwritten function in R software for PDT time at depth (TAD bins $0,5,10,20,30,50,70,100,150,200,250,400$, 
600 and $>600 \mathrm{~m}$ ) and time at temperature (TAT bins 2, $4,6,8,10,12,13,14,15,16,17,19,21,>21{ }^{\circ} \mathrm{C}$ ) analysis. Diel periods were split following algorithm provided by the National Oceanic \& Atmospheric Administration (NOAA) in the website http://www.esrl.noaa.gov/gmd/ $\mathrm{grad} /$ solcalc/sunrise.html. Data from bins encompassing either sunrise or sunset hours were excluded from the analysis, assuring no night hours are wrongly considered in daylight period or vice versa. Diel depth and temperature data were then plotted as frequency histograms by summarising both the TAD and TAT matrices into a 24-h window and by averaging the depth (or temperature) attained at every four (or six) hours. A total of nine individuals were tracked with these depth recorders, of which only two had lengths greater than the averaged $0.92 \mathrm{~m}$ in this study, which hampers statistical analysis per sunfish size class. However, correlations (Spearman rank correlations, as data failed normality test) of time spent at deep layers $(>250 \mathrm{~m})$ and surface $(\leq 5 \mathrm{~m})$ were run per individual to inform on possible size differences in vertical usage. In addition, using information recorded on both minimum and maximum depth (from the retrieved PDT data) the vertical extent was summarised per individual sunfish. Spearman correlations were also computed to determine whether water column occupancy amplitudes varied with sunfish sizes.

To detect changes in depth occupancy, the TAD matrix was inspected using a modified version of the split moving window method (SMW) to detect significant shifts in time-at-depth data defining behavioural phases [8]. This method comprises a variable-sized split window with temporal scales ranging from $4 \mathrm{~h}$ up to 5 days to calculate dissimilarities between the two halves of the window along the time steps of the vertical track. Euclidean dissimilarity between different halves is then assigned to the centre of the window. The process was repeated moving one step forward until the window reached the end of the data series. Statistical significance of dissimilarities for each window central point denote where the profile should be split (see $[4,8])$. Diel vertical habitat use (TAD and TAT) was then analysed per sunfish trajectory section. To compare daytime and night-time temperature preferences within each SMW section, we used nonparametric two-sample Kolmogorov-Smirnov $(\mathrm{K}-\mathrm{S})$ tests for the TAT obtained, in R. Lastly, retrieved PDT data of simultaneous depth and temperature information at each temporal interval ( 4 or $6 \mathrm{~h}$ ) were used to characterise sunfish occupied water column (revealed by the variance of temperature with depth). Briefly, averages derived from the minimum and maximum temperatures recorded for each depth bin occupied within the 4 or $6 \mathrm{~h}$ summarised data set, were calculated. Final means and standard deviations for each depth recorded (m) with associated temperature were then computed pooling from each of the sunfish SMW determined section.

\section{Additional files}

Additional file 1: Figure S1. Sunfish displacement per size. A) Daily displacement in relation to time, coloured according to sunfish size; B) Boxplots of the size-related displacements; C) Average daily distance form tagging location, per Julian day also coloured by sunfish size. Red dots denote displacement of sunfish smaller than the average TL (0.92 m) and black for larger individuals.

Additional file 2: Table S1. Coefficients of the overall RSPF model of sunfish distribution. Model coefficients are shown for each of the four variables selected for modelling the probability of occurrence of sunfish, within the species $95 \%$ MCP based on tracked individuals.

Additional file 3: Table S2. Relative importance of each variable to the final model. Step-wise models were generated excluding each variable at a time and deviances were calculated informing on the significance of each parameter to the full model (deviance, $A I C, \triangle$ deviance, $\triangle A I C, p$ value, relative likelihood and WAIC). Clearly, gradients of SST and SST were the most influent variables providing the highest \% of significant variability explained ( $\triangle$ deviance) and both features had the lowest wAIC if removed.

Additional file 4: Table S3. Seasonal model coefficients output. Individual variable importance also shown by the wAIC column of each model.

Additional file 5: Table S4. Statistical output from the seasonal models goodness of fit (GOF).

Additional file 6: Figure S2. Sunfish time at depth histograms. General depth occupancy for tracked sunfish pooled from the entire dataset.

Additional file 7: Figure S3. Vessel monitoring system of longliner fleets operating in the north-east Atlantic at $25 \mathrm{~km}$ grid cells. Both Portuguese and Spanish VMS data on pelagic longliners operating in the region were gathered for the period 2003-2011 and vessel GPS positions were filtered to remove all non-fishing travels. Resultant fishing operations were gridded at $0.25^{\circ}$ cell sizes and number of positions were counted per grid cell which are coloured accordingly.

\section{Abbreviations}

GPS: global positioning system; TL: total length; RSPF: resource selection probability functions; GOF: goodness of fit; SST: sea surface temperature; DVM: diel vertical migration; PSAT: pop-up satellite archival tag; SPOT: satellite-linked 'smart' position only transmitter; LC: location class; WC-GPE: Wildlife Computers Global Position Estimator; UKFsst: unscented Kalman filter; MCP: minimum convex polygon; KDE: kernel density estimator; AVHRR: advanced very highresolution radiometer; NOAA: National Oceanic and Atmospheric Administration; MODIS: Moderate Resolution Imaging Spectrometer; TAD: time at depth; TAT: time-at-temperature SMW: split moving window; SMW: split moving window; PT: poor transmission; DNR: did not report; nDVM: normal diel vertical migration; rDVM: reverse diel vertical migration; MPA: marine protected areas.

\section{Authors' contributions}

LLS, NQ and DWS conceived and designed the experiments. LLS, NQ, DWS and GM performed the experiments. LLS, NQ and DWS analysed the data. NEH contributed reagents/materials/analysis tools. LLS, NQ and DWS wrote the paper. All authors read and approved the final manuscript.

\section{Author details}

${ }^{1}$ Marine Biological Association of the United Kingdom, The Laboratory, Citadel Hill, Plymouth PL1 2PB, UK. ${ }^{2}$ CIBIO-InBIO, Centro de Investigação em Biodiversidade e Recursos Genéticos, Campus Agrário de Vairão, Universidade do Porto, 4485-661 Vairão, Portugal. ${ }^{3}$ Ocean and Earth Science, National Oceanography Centre Southampton, University of Southampton, Waterfront Campus, Southampton SO14 3ZH, UK. ${ }^{4}$ Centro Tecnológico del Mar - Fundación CETMAR, 36208 Vigo, Spain. ${ }^{5}$ Centre for Biological Sciences, Highfield Campus, University of Southampton, Southampton SO17 1BJ, UK. 


\section{Acknowledgements}

We thank G. Hays, J. Houghton and T. Doyle for tagging two sunfish in Ireland, G. Hays for contributing funds to purchase four Argos-GPS tags, and all the crew in Tunipex S.A., especially both Mr Morikawa and captain Alfredo, for allowing access to the tuna pen and for much valued field support, without which the current study would not have been possible. Funding was provided by the FCT through a PhD Scholarship (SFRH/BD/68717/2010) to L.L.S. and Investigator Fellowship to N.Q. (IF/01611/2013). We gratefully acknowledge funding from Oceanário de Lisboa to purchase two Argos-GPS tags, and the UK Natural Environment Research Council (NERC) Oceans 2025 Strategic Research Programme (Theme 6 Science for Sustainable Marine Resources) in which D.W.S. was a principal investigator. D.W.S. was also supported by a Marine Biological Association (MBA) Senior Research Fellowship.

\section{Competing interests}

The authors declare that they have no competing interests.

Received: 3 February 2015 Accepted: 22 January 2016

Published online: 08 February 2016

\section{References}

1. Chapman BB, Hulthén K, Brodersen J, Nilsson PA, Skov C, Hansson LA, et al. Partial migration in fishes: causes and consequences. J Fish Biol. 2012;81(2):456-78. doi:10.1111/j.1095-8649.2012.03342.x.

2. Weng KC, Foley DG, Ganong JE, Perle C, Shillinger GL, Block BA. Migration of an upper trophic level predator, the salmon shark Lamna ditropis, between distant ecoregions. Mar Ecol Prog Ser. 2008;372:253-64. doi:10.3354/meps07706.

3. Gurarie E, Andrews RD, Laidre KL. A novel method for identifying behavioural changes in animal movement data. Ecol Lett. 2009;12(5):395-408. doi:10.1111/j.1461-0248.2009.01293.x.

4. Humphries NE, Queiroz N, Dyer JRM, Pade NG, Musyl MK, Schaefer KM, et al. Environmental context explains Lévy and Brownian movement patterns of marine predators. Nature. 2010;465(7301):1066-9. doi:10.1038/ nature09116.

5. Sims DW. Tracking and analysis techniques for understanding free-ranging shark movements and behavior. In: Carrier JC, Musick JA, Heithaus MR, editors. Sharks and their relatives II: biodiversity, adaptive physiology, and conservation. 1st ed. Boca Raton, FL: CRC Press; 2010. p. 351-96.

6. Block BA, Jonsen ID, Jorgensen SJ, Winship AJ, Shaffer SA, Bograd SJ, et al. Tracking apex marine predator movements in a dynamic ocean. Nature. 2011:475:86-90. doi:10.1038/nature10082.

7. Walli A, Teo SLH, Boustany A, Farwell CJ, Williams T, Dewar H, et al. Seasonal movements, aggregations and diving behavior of Atlantic bluefin tuna (Thunnus thynnus) revealed with archival tags. PLoS ONE. 2009:4(7):e6151. doi:10.1371/journal.pone.0006151.

8. Queiroz N, Humphries NE, Noble LR, Santos AM, Sims DW. Short-term movements and diving behaviour of satellite-tracked blue sharks Prionace glauca in the northeastern Atlantic Ocean. Mar Ecol Prog Ser. 2010;406:265-79. doi:10.3354/meps08500.

9. Queiroz N, Humphries NE, Noble LR, Santos AM, Sims DW. Spatial dynamics and expanded vertical niche of blue sharks in oceanographic fronts reveal habitat targets for conservation. PLoS ONE. 2012;7(2):e32374. doi:10.1371/journal.pone.0032374.

10. Shepard ELC, Ahmed MZ, Southall EJ, Witt MJ, Metcalfe JD, Sims DW. Diel and tidal rhythms in diving behaviour of pelagic sharks identified by signal processing of archival tagging data. Mar Ecol Prog Ser. 2006;328:20513. doi:10.3354/meps328205.

11. Louzao M, Pinaud D, Péron C, Delord K, Wiegand T, Weimerskirch H. Conserving pelagic habitats: seascape modelling of an oceanic top predator. J Appl Ecol. 2011;48(1):121-32. doi:10.1111/j.1365-2664.2010.01910.x.

12. Lutcavage ME, Brill RW, Skomal GB, Chase BC, Howey PW. Results of popup satellite tagging of spawning size class fish in the Gulf of Maine: do North Atlantic bluefin tuna spawn in the mid-Atlantic? Can J Fish Aquat Sci. 1999;56:173-7. doi:10.1139/f99-016.

13. Sedberry GR, Loefer J. Satellite telemetry tracking of swordfish, Xiphias gladius, off the eastern United States. Mar Biol. 2001;139(2):355-60. doi: $10.1007 / 5002270100593$.
14. Abascal FJ, Quintans M, Ramos-Cartelle A, Mejuto J. Movements and environmental preferences of the shortfin mako, Isurus oxyrinchus, in the southeastern Pacific Ocean. Mar Biol. 2011;158(5):1175-84. doi:10.1007/ s00227-011-1639-1.

15. Mansfield KL, Saba VS, Keinath JA, Musick JA. Satellite tracking reveals a dichotomy in migration strategies among juvenile loggerhead turtles in the Northwest Atlantic. Mar Biol. 2009;156(12):2555-70. doi:10.1007/ s00227-009-1279-X.

16. Scales KL, Miller PI, Hawkes LA, Ingram SN, Sims DW, Votier SC. On the Front Line: frontal zones as priority at-sea conservation areas for mobile marine vertebrates. J Appl Ecol. 2014;51(6):1575-83. doi:10.1111/1365-2664.12330.

17. Polovina JJ, Howell E, Kobayashi DR, Seki MP. The transition zone chlorophyll front, a dynamic global feature defining migration and forage habitat for marine resources. Prog Oceanogr. 2001;49(1-4):469-83. doi:10.1016/S0079-6611(01)00036-2.

18. McKinney JA, Hoffmayer ER, Wu W, Fulford R, Hendon J. Feeding habitat of the whale shark Rhincodon typus in the northern Gulf of Mexico determined using species distribution modelling. Mar Ecol Prog Ser. 2012:458:199-211. doi:10.3354/meps09777.

19. Hays GC, Hobson VJ, Metcalfe JD, Righton D, Sims DW. Flexible foraging movements of leatherback turtles across the North Atlantic Ocean. Ecology. 2006;87(10):2647-56. doi:10.1890/0012-9658(2006)87[2647:FFMOLT] 2.0.CO;2.

20. Johnson JB, Omland KS. Model selection in ecology and evolution. Trends Ecol Evol. 2004;19(2):101-8. doi:10.1016/j.tree.2003.10.013.

21. Guisan A, Zimmermann NE. Predictive habitat distribution models in ecology. Ecol Model. 2000;135(2-3):147-86. doi:10.1016/ S0304-3800(00)00354-9.

22. Olden JD, Lawler JJ, Poff NL. Machine learning methods without tears: a primer for ecologists. Q Rev Biol. 2008;83(2):171-93. doi:10.1086/587826.

23. Guisan A, Edwards TC Jr, Hastie T. Generalized linear and generalized additive models in studies of species distributions: setting the scene. Ecol Model. 2002;157(2-3):89-100. doi:10.1016/S0304-3800(02)00204-1.

24. Guisan A, Graham CH, Elith J, Huettmann F. Sensitivity of predictive species distribution models to change in grain size. Divers Distrib. 2007;13(3):332-40. doi:10.1111/j.1472-4642.2007.00342.x.

25. Elith J, Leathwick JR. Species distribution models: ecological explanation and prediction across space and time. Annu Rev Ecol Evol Syst. 2009:40(1):677-97. doi:10.1146/annurev.ecolsys.110308.120159.

26. Abecassis M, Dewar H, Hawn D, Polovina J. Modg swordfish daytime vertical habitat in the North Pacific Ocean from pop-up archival tags. Mar Ecol Prog Ser. 2012;452:219-36. doi:10.3354/meps09583.

27. Zydelis R, Lewison RL, Shaffer SA, Moore JE, Boustany AM, Roberts JJ, et al. Dynamic habitat models: using telemetry data to project fisheries bycatch. Proc R Soc B Biol Sci. 2011;278:3191-200. doi:10.1098/ rspb.2011.0330

28. Manly BFJ, McDonald LL, Thomas DL, McDonald TL, Erickson WP. Resource selection by animals. Statistical design and analysis for field studies. 2nd ed. Netherlands: Springer; 2002.

29. Boyce MS. Scale for resource selection functions. Divers Distrib. 2006;12(3):269-76. doi:10.1111/j.1366-9516.2006.00243.x.

30. Chetkiewicz C-LB, Boyce MS. Use of resource selection functions to identify conservation corridors. J Appl Ecol. 2009;46:1036-47. doi:10.1111/ jpe.2009.46.issue-5.

31. Lele SR. A new method for estimation of resource selection probability function. J Wildl Manag. 2009;73(1):122-7. doi:10.2193/2007-535.

32. Boyce MS, MCDonald LL. Relating populations to habitat using resource selection functions. Trends Ecol Evol. 1999;14(7):268-72. doi:10.1016/ S0169-5347(99)01593-1.

33. Cartamil DP, Lowe CG. Diel movement patterns of ocean sunfish Mola mola off southern California. Mar Ecol Prog Ser. 2004;266:245-53. doi:10.3354/meps266245.

34. Sims DW, Queiroz N, Humphries NE, Lima FP, Hays GC. Long-term GPS tracking of Ocean sunfish Mola mola offers a new direction in fish monitoring. PLOS ONE. 2009;4(10):e7351. doi:10.1371/journal.pone.0007351. t001.

35. Sims DW, Queiroz N, Doyle TK, Houghton JDR, Hays GC. Satellite tracking of the World's largest bony fish, the ocean sunfish (Mola mola L.) in the North East Atlantic. J Exp Mar Biol Ecol. 2009;370(1-2):127-33. doi:10.1016/j.jembe.2008.12.011 
36. Dewar H, Thys TM, Teo SLH, Farwell C, O'Sullivan J, Tobayama T, et al. Satellite tracking the world's largest jelly predator, the ocean sunfish, Mola mola, in the Western Pacific. J Exp Mar Biol Ecol. 2010;393:32-42. doi:10.1016/j.jembe.2010.06.023.

37. Potter IF, Galuardi B, Howell WH. Horizontal movement of ocean sunfish, Mola mola, in the northwest Atlantic. Mar Biol. 2010;158(3):531-40. doi:10.1007/s00227-010-1578-2.

38. Parsons TR, Takahashi M, Hargrave B. Biological oceanographic processes. 3rd ed. Oxford: Pergamon Press; 1984.

39. Potter IF, Howell WH. Vertical movement and behavior of the ocean sunfish, Mola mola, in the northwest Atlantic. J Exp Mar Biol Ecol. 2011;396(2):138-46. doi:10.1016/j.jembe.2010.10.014.

40. Sims DW, Southall EJ, Humphries NE, Hays GC, Bradshaw CJ, Pitchford JW, et al. Scaling laws of marine predator search behaviour. Nature. 2008;451(7182):1098-102. doi:10.1038/nature06518.

41. Gunn JS, Stevens JD, Davis TLO, Norman BM. Observations on the short-term movements and behaviour of whale sharks (Rhincodon typus) at Ningaloo Reef, western Australia. Mar Biol. 1999;135(3):553-9. doi:10.1007/s002270050656.

42. Sims DW, Southall EJ. Occurence of ocean sunfish, Mola mola near fronts in the western English Channel. J Mar Biol Assoc UK. 2002;82(5):927-8. doi:10.1017/S0025315402006409.

43. Lam CH, Nielsen A, Sibert JR. Incorporating sea-surface temperature to the light-based geolocation model Tracklt. Mar Ecol Prog Ser. 2010;419:71-84. doi:10.3354/meps08862.

44. Sippel T, Holdsworth J, Dennis T, Montgomery J. Investigating behaviour and population dynamics of striped marlin (Kajikia audax) from the southwest Pacific Ocean with satellite tags. PLOS ONE. 2011;6(6):e21087. doi:10.1371/journal.pone.0021087.

45. Schaefer K, Fuller D, Hampton J, Caillot S, Leroy B, Itano D. Movements, dispersion, and mixing of bigeye tuna (Thunnus obesus) tagged and released in the equatorial Central Pacific Ocean, with conventional and archival tags. Fish Res. 2015;161:336-55. doi:10.1016/j.fishres.2014.08.018.

46. Burnham KP, Anderson DR. Model selection and multimodel inference: a practical information-theoretic approach. Berlin: Springer Science \& Business Media; 2002

47. Leeney RH, Witt MJ, Broderick AC, Buchanan J, Jarvis DS, Richardson PB, et al. Marine megavertebrates of Cornwall and the Isles of Scilly: relative abundance and distribution. J Mar Biol Assoc UK. 2011;92(08):1823-33. doi:10.1017/s002531541100155x.

48. McMahon CR, Hays GC. Thermal niche, large-scale movements and implications of climate change for a critically endangered marine vertebrate. Glob Change Biol. 2006;12(7):1330-8. doi:10.1111/j.1365-2486.2006.01174.x.

49. Pope EC, Hays GC, Thys TM, Doyle TK, Sims DW, Queiroz N, et al. The biology and ecology of the ocean sunfish Mola mola: a review of current knowledge and future research perspectives. Rev Fish Biol Fish. 2010;20(4):471-87. doi:10.1007/s11160-009-9155-9.

50. Sims DW, Fox AM, Merrett DA. Basking shark occurrence off southwest England in relation to zooplankton abundance. J Fish Biol. 1997;51(2):436-40. doi:10.1111/j.1095-8649.1997.tb01677.x.

51. Sims DW, Quayle VA. Selective foraging behaviour of basking sharks on zooplankton in a small-scale front. Nature. 1998;393:460-4. doi:10.1038/30959.

52. Chavez FP, Messié M. A comparison of eastern boundary upwelling ecosystems. Prog Oceanogr. 2009;83(1):80-96. doi:10.1016/j. pocean.2009.07.032

53. Nur N, Jahncke J, Herzog MP, Howar J, Hyrenbach KD, Zamon JE, et al. Where the wild things are: predicting hotspots of seabird aggregations in the California Current System. Ecol Appl. 2011;21(6):2241-57. doi:10.1890/10-1460.1.

54. Siokou-Frangou I, Christaki U, Mazzocchi MG, Montresor M, Ribera d'Alcalá M, Vaqué D, et al. Plankton in the open Mediterranean Sea: a review. Biogeosciences. 2010;7(5):1543-86. doi:10.5194/bg-7-1543-2010.

55. Stevenson R. Huelva Front and Malaga, Spain, eddy chain as defined by satellite and oceanographic data. Deutsche Hydrographische Zeitschrift. 1977;30(2):51-3. doi:10.1007/BF02226082.

56. Criado-Aldeanueva F, García-Lafuente J, Navarro G, Ruiz J. Seasonal and interannual variability of the surface circulation in the eastern Gulf of Cadiz (SW Iberia). J Geophys Res Oceans. 2009;114(C1):C01011. doi:10.102 9/2008JC005069.
57. Catalán IA, Rubín JP, Navarro G, Prieto L. Larval fish distribution in two different hydrographic situations in the Gulf of Cádiz. Deep Sea Res Part II. 2006;53(11-13):1377-90. doi:10.1016/j.dsr2.2006.04.010.

58. Moreno A, Dos Santos A, Piatkowski U, Santos AMP, Cabral H. Distribution of cephalopod paralarvae in relation to the regional oceanography of the western Iberia. J Plankton Res. 2009;31(1):73-91. doi:10.1093/plankt/ fbn103.

59. Sobrino I, García T, et al. Reproductive aspects of the rose shrimp Parapenaeus longirostris (Lucas, 1846) in the Gulf of Cadiz (southwestern Iberian Peninsula). Bolletin Instuto Espanhol Oceanografia. 2007;23(1-4):57-71.

60. Pade NG, Queiroz N, Humphries NE, Witt MJ, Jones CS, Noble LR, et al. First results from satellite-linked archival tagging of porbeagle shark, Lamna nasus: area fidelity, wider-scale movements and plasticity in diel depth changes. J Exp Mar Biol Ecol. 2009;370(1-2):64-74. doi:10.1016/j. jembe.2008.12.002.

61. Thys TM, Ryan JP, Dewar H, Perle CR, Lyons K, O'Sullivan J, et al. Ecology of the Ocean Sunfish, Mola mola, in the southern California Current System. J Exp Mar Biol Ecol. 2015;471:64-76. doi:10.1016/j.jembe.2015.05.005.

62. Sims DW, Witt MJ, Richardson AJ, Southall EJ, Metcalfe JD. Encounter success of free-ranging marine predator movements across a dynamic prey landscape. Proc R Soc B Biol Sci. 2006;273(1591):1195-201. doi:10.1098/ rspb.2005.3444.

63. Sims DW, Southall EJ, Richardson AJ, Reid PC, Metcalfe JD. Seasonal movements and behaviour of basking sharks from archival tagging: no evidence of winter hibernation. Mar Ecol Prog Ser. 2003;248:187-96. doi:10.3354/meps248187.

64. Boyce MS, Vernier PR, Nielsen SE, Schmiegelow FKA. Evaluating resource selection functions. Ecol Model. 2002;157(2-3):281-300. doi:10.1016/ S0304-3800(02)00200-4.

65. Carey FG, Scharold JV. Movements of blue sharks (Prionace glauca) in depth and course. Mar Biol. 1990;106:329-42. doi:10.1007/BF01344309.

66. Nakamura I, Goto Y, Sato K. Ocean sunfish rewarm at the surface after deep excursions to forage for siphonophores. J Anim Ecol. 2015: doi:10.1111/1365-2656.12346.

67. Hays GC, Bastian T, Doyle TK, Fossette S, Gleiss AC, Gravenor MB, et al. High activity and Levy searches: jellyfish can search the water column like fish. Proc R Soc B Biol Sci. 2012;279(1728):465-73. doi:10.1098/ rspb.2011.0978.

68. Sims DW, Southall EJ, Tarling GA, Metcalfe JD. Habitat-specific normal and reverse diel vertical migration in the plankton-feeding basking shark. J Anim Ecol. 2005;74(4):755-61. doi:10.1111/j.1365-2656.2005.00971.x.

69. Nakamura I, Sato K. Ontogenetic shift in foraging habit of ocean sunfish Mola mola from dietary and behavioral studies. Mar Biol. 2014:161(6):1263-73. doi:10.1007/s00227-014-2416-8.

70. Syvaranta J, Harrod C, Kubicek L, Cappanera V, Houghton JD. Stable isotopes challenge the perception of ocean sunfish Mola mola as obligate jellyfish predators. J Fish Biol. 2012;80(1):225-31. doi:10.1111/j.1095-8649.2011.03163.x.

71. Bigelow KA, Boggs $\mathrm{CH}, \mathrm{He}$ X. Environmental effects on swordfish and blue shark catch rates in the US North Pacific longline fishery. Fish Oceanogr. 1999;8(3):178-98. doi:10.1046/j.1365-2419.1999.00105.x.

72. Nakatsubo T, Kawacxt M, Marro N, Hirose H. Estimation of maturation in wild and captive ocean sunfish Mola mola. Aquac Sci. 2007;55(2):259-64. doi:10.11233/aquaculturesci1953.55.259.

73. Costa DP, Robinson PW, Arnould JPY, Harrison A-L, Simmons SE, Hassrick $J$, et al. Accuracy of ARGOS locations of pinnipeds at-Sea estimated using Fastloc GPS. PLoS ONE. 2010;5(1):e8677. doi:10.1371/journal. pone.0008677.

74. Lam C, Nielsen A, Sibert J. Improving light and temperature based geolocation by unscented Kalman filtering. Fish Res. 2008;91(1):15-25 doi:10.1016/j.fishres.2007.11.002

75. Johnson DS, London JM, Lea M-A, Durban JW. Continuous-time correlated random walk model for animal telemetry data. Ecology. 2008;89(5):1208-15. doi:10.1890/07-1032.1.

76. Patterson TA, McConnell BJ, Fedak MA, Bravington MV, Hindell MA. Using GPS data to evaluate the accuracy of state-space methods for correction of Argos satellite telemetry error. Ecology. 2010;91(1):273-85. doi:10.1890/08-1480.1

77. Zuur A, leno EN, Walker N, Saveliev AA, Smith GM. Mixed effects models and extensions in ecology with R. Berlin: Springer Science \& Business Media; 2009. 